\title{
The geologic role of polysulfides-Part I \\ The distribution of ionic species in aqueous sodium polysulfide solutions*
}

\author{
Paul L. Cloke \\ Department of Geology and Mineralogy, University of Michigan
}

(Received 31 January 1963; accepted 26 May 1963)

\begin{abstract}
Numerous measurements have been made of the $\mathrm{pH}, \mathrm{Eh}$, and the potential of a silver-silver sulfide electrode in sodium sulfide and sodium polysulfide solutions. By suitably estimating the second dissociation constant of hydrogen sulfide and various activity coefficients, it has been possible to derive a consistent model for the distribution of the polysulfide and sulfide species, $\mathrm{S}^{-2}, \mathrm{~S}_{4}^{-2}, \mathrm{~S}_{5}{ }^{-2}, \mathrm{~S}_{6}^{-2}$ and $\mathrm{H}^{-1}$, at strengths up to $1 \mathrm{M}$ and for $\mathrm{pH}$ values between 7 and 13. This model differs markedly from the models given previously by Peschanski and Valensi (1949) and by Maronny (1959b), who include $\mathrm{S}^{-2}, \mathrm{~S}_{2}^{-2}, \mathrm{~S}_{3}^{-2}, \mathrm{~S}_{4}^{-2}, \mathrm{~s}_{5}^{-2}$ and $\mathrm{HS}^{-1}$. The free energy of formation values proposed here are $16 \cdot 36 \pm 0 \cdot 10 \mathrm{kcal} /$ mole for $S_{6}{ }^{-2}, 15.97 \pm 0 \cdot 10$ $\mathrm{kcal} / \mathrm{mole}$ for $\mathrm{S}_{5}{ }^{-2}$, and $16 \cdot 29 \pm 0 \cdot 10 \mathrm{kcal} / \mathrm{mole}$ for $\mathrm{S}_{4}{ }^{-2}$. Tentative figures for di- and tri-sulfide ions are $21 \cdot 0+3 \cdot 0 \mathrm{kcal} / \mathrm{mole}$ for $\mathrm{S}_{3}{ }^{-2}$ and $22 \cdot 7 \pm 3.0 \mathrm{kcal} / \mathrm{mole}$ for $\mathrm{S}_{2}{ }^{-2}$. These are based on a value of $21.42 \mathrm{kcal} /$ mole for $\mathrm{s}^{-2}$.
\end{abstract}

\section{INTRODUCTION}

THIs paper is the first of a series dealing with the possible role of polysulfide solutions in the transport and deposition of chalcophile elements in sulfide vein deposits. The suggested $\mathrm{Eh}$ and $\mathrm{pH}$ values for the hydrothermal solution (BARToN, 1957; NataRaJan, 1958) lie close to the stability field of elemental sulfur. Since this is exactly the region where polysulfides have their greatest thermodynamic stability, it seems logical that metal-polysulfide complexes may explain hydrothermal transport (BARTon, 1957; BaRnes, 1958). Moreover, several sulfides have rather high solubilities in polysulfide solutions.

In order to test this idea further and to determine the influence of changing $\mathrm{pH}$ on solubilities, experiments on the solubility of acanthite, $\mathrm{Ag}_{2} \mathrm{~S}$, were begun. It soon became apparent that an understanding of the observed solubilities must be based on an adequate interpretation of the distribution of polysulfide ions in aqueous solutions. It is the purpose of this paper to discuss this interpretation and to present the distribution derived from new experimental work. Subsequent papers will deal with the observed solubilities and the significance for geologic processes.

\section{Terminologr}

The following definitions and explanations of terms and symbols will be helpful to the roader in understanding the text.

$A$, a temperature dependent constant in the Debye-Hückel equation.

$a_{0}$, the "mean distance of closest approach" as used in the Debye-Hückel equation.

$B$, a temperature dependent constant in the Debye-Hückel equation.

c oquals $\left[\mathrm{HS}^{-1}\right]+\sum_{x=1}^{\infty}\left[\mathrm{S}_{x}^{-2}\right]$.

$F^{\circ}$, a standard potential; the sign convention of the American Elcetrochemical Society is used. Eh, the oxidation potential in an aqueous solution.

* Published under the auspices of the Committee on Experimental Geology and Geophysics and the Division of Geological Sciences at Harvard University. 
$E_{I}{ }^{\circ}$, the standard potential for the reaction, $\mathrm{S}^{-2}=\mathrm{S}+2 e^{-1}$.

$E_{x}$, the standard potential for the reactions, $x \mathrm{~S}^{-2}=\mathrm{S}_{x}^{-2}+2(x-1) \mathrm{e}^{-1}$, where $x$ is an integer.

$e^{-}$, symbol for an electron in an oxidation-reduction reaction.

$\Delta^{\mathbf{1}} F^{\circ}$ standard Gibbs free energy of reaction or of formation.

$\Delta F^{\circ}{ }_{N}$ standard Gibbs free energy of formation of the substance $N$, where $N$ represents the chemical formula of the substance.

$f_{N}$, rational activity coefficient of the substance $N$.

$\gamma^{\prime}{ }^{z}$, stoichiometric molar activity coefficient of the ion $N$; where $N$ represents the chemical formula of the ion and $z$ its charge.

$\gamma^{\prime} \pm Q_{q} R_{r}$, mean molar ionic activity coefficient of the ionic compound $Q_{q} R_{r}$.

$\gamma_{+}$, molar ionic activity coefficient of a cation.

$\gamma_{-}$, molar ionic activity coefficient of an anion.

$\gamma_{ \pm}$, mean molar ionic activity coefficient.

hydropolysulfide ion, one of the ions, $\mathrm{HS}_{x}^{-1}$, where $x$ is an integer greater than 1 .

$K$, an equilibrium constant.

$K_{w}$, the dissociation constant of water, equal to $\left(\mathrm{H}^{+1}\right)\left(\mathrm{OH}^{-1}\right)$;

$K_{1}$, the first dissociation constant of $\mathrm{H}_{2} \mathrm{~S}$ equal to the ratio $\left(\mathrm{H}^{+1}\right)\left(\mathrm{HS}^{-1}\right) /\left(\mathrm{H}_{2} \mathrm{~S}\right)$.

$K_{2}$, the second dissociation constant of $\mathrm{H}_{2} \mathrm{~S}$ equal to the ratio $\left(\mathrm{H}^{+1}\right)\left(\mathrm{S}^{-2}\right) /\left(\mathrm{HS}^{-1}\right)$.

$K_{5}{ }^{\prime}$, the equilibrium constant $\left(\mathrm{S}_{5}{ }^{-2}\right)^{3}\left(\mathrm{~S}^{-2}\right) /\left(\mathrm{S}_{4}{ }^{-2}\right)^{4}$.

$K_{5}{ }^{\prime \prime}$, the equilibrium constant $\left(\mathrm{S}_{5}{ }^{-2}\right) /\left(\mathrm{S}_{4}{ }^{-2}\right)$.

$K_{6}{ }^{\prime}$, the equilibrium constant $\left.\left(\mathrm{S}_{6}{ }^{-2}\right)^{4}\left(\mathrm{~S}^{-2}\right) / \mathrm{S}_{5}{ }^{-2}\right)^{5}$.

$\mathrm{M}$, inolarity of a substance in solution.

monosulfide, the sum $\sum_{x=1}^{\infty}\left\{\left[\mathrm{H}_{2} \mathrm{~S}_{x}\right]+\left[\mathrm{HS}_{x}{ }^{-1}\right]+\left[\mathrm{S}_{x}^{-2}\right]\right\}$, where $x$ is an integer.
mv, millivolts.

$\mathrm{m} \mu$, millimicrons.

$\mu$, ionic strength.

$(N)$, the activity of the substance $N$ in moles/l.

$[N]$, the concentration of the substance $N$ in moles/l.

persulfide, the highly-colored oil produced by adding aqueous polysulfide solutions to cold concentrated $\mathrm{HCl}$; a mixture of various hydrogen polysulfides.

$\mathrm{p} K$, the negative decadic $\log$ of $K$.

$\mathrm{p} N$, the negative decadic $\log$ of $(N)$.
polysulfide, (a) when used as a noun, polysulfide means the sum, $\sum_{x=2}^{\infty}(x-1)\left\{\left[\mathrm{S}_{x}^{-2}\right]+\left[\mathrm{HS}_{x}{ }^{-1}\right]+\right.$

$\left.\left[\mathrm{H}_{2} \mathrm{~S}_{x}\right]\right\}$; where $x$ is an integer; the sum of monosulfide and polysulfide equals the total amount of $\mathrm{S}$ contained in all sulfide and polysulfide species present,

(b) when used as an adjective, polysulfide means "containing or composed of one or more polysulfide species."

polysulfides, the plural of polysulfide species.

polysulfide ion, one of the ions, $\mathrm{S}_{x}^{-2}$, where $x$ is an integer greater than 1 .

polysulfide species, a compound, molecule, or ion containing the group, $\mathrm{s}_{x}{ }^{-2}$, where $x$ is an integer greater than 1, and not containing oxygen; the negative two charge indicated may be satisfied wholly or in part by covalent bonds. The average valence of the sulfur is botween 0 and -2 .

$Q_{q} R_{r}$, an ionic compound containing $q$ cations of element $Q$ and $r$ anions of element $R$.

$q$, the (integral) number of cations in $Q_{q} R_{r}$.

$r$, the (integral) number of anions in $Q_{q} R_{r}$.

sulfane, one of the polysulfide species $\mathrm{H}_{2} \mathrm{~S}_{x}$, where $x$ is an integer greater than 1 .

sulfide, as a noun; a compound, molecule, or ion containing sulfur having an average valence of -2 .

as an adjective; the word sulfide refers to the presence of a sulfide.

species, a solid compound or all of the molecules or all of the ions which can be represented by a single chemical formula.

$t$, temperature in ${ }^{\circ} \mathrm{C}$. 
$\mathrm{V}$, volts.

$x$, the number of atoms of sulfur in a sulfide or polysulfide species.

$\bar{x}$, the ratio $\sum_{x=2}^{\infty} \mathrm{x}\left\{\left[\mathrm{H}_{2} \mathrm{~S}_{x}\right]+\left[\mathrm{HS}_{x}^{-1}\right]+\left[\mathrm{S}_{x}{ }^{-2}\right]\right\} / \sum_{x=2}^{\infty}\left\{\left[\mathrm{H}_{2} \mathrm{~S}_{x}\right]+\left[\mathrm{HS}_{x}{ }^{-1}\right]+\left[\mathrm{S}_{x}{ }^{-2}\right]\right\}$

the average value of $x$ in all polysulfides in solution.

$\bar{y}$, the ratio of the sum of monosulfide plus polysulfide to monosulfide; the average value of $x$ in all polysulfides and sulfides in solution.

$z$, the charge on an ion.

\section{Previous Work}

The earlier work dealing with aqueous solutions of alkali sulfides is rather extensive. Attention will be focused mostly on work with polysulfide solutions instead of on a review of all the pertinent literature. However, values of certain constants derived from work with sulfides are of interest.

\section{Dissociation constants of $\mathrm{H}_{2} \mathrm{~S}$}

Values reported for the second dissociation constant of $\mathrm{H}_{2} \mathrm{~S}$ range over several orders of magnitude. Some of the more recent values for the logarithm of this constant are $-14.00\left(25^{\circ} \mathrm{C}\right)$ (Eluis and Goldiva, 1959), - 13.90 (25 $5^{\circ} \mathrm{C}$ )(Maronny, 1959a), - $12.89\left(25^{\circ} \mathrm{C}\right)$ (Kury, Zielen, and LATIMER, 1953, using data recalculated from KoNopiK and LEBERL, 1949), $-14.00\left(25^{\circ} \mathrm{C}\right)$ (Latimer, 1952), $-13 \cdot 10\left(20^{\circ} \mathrm{C}\right)$ (KoNopIK and Lebert, 1949), and $-12 \cdot 44\left(20^{\circ} \mathrm{C}\right)$ (KuBLI, 1946). A considerably older value is $-14.9\left(25^{\circ} \mathrm{C}\right)$ (KNox, 1908).

For the first dissociation constant of $\mathrm{H}_{2} \mathrm{~S}$ the value of $1.02 \times 10^{-7}$ as given by KURY, ZIELEN, and LATIMER (1953) was accepted.

\section{Work with sodium polysulfides}

Küster and HeBERLeIN (1905) studied the solubility of $\mathrm{S}$ in $\mathrm{Na}_{2} \mathrm{~S}$ solutions. They found that $\bar{y}$ varied from 4.47 to $5 \cdot 24$ at $25^{\circ} \mathrm{C}$ depending on the concentration. For a $1 \mathrm{~N}(1 \mathrm{M}$ in sodium ion) solution they found that the solubility decreased very slightly with increasing temperature. By considering the properties expected to be associated with various possible molecular structures (mostly the expected strengths of the acids, $\mathrm{H}_{2} \mathrm{~S}_{x}$ ), they concluded that the most likely structure for the acids was a chain designated as $\mathrm{H}_{2} \mathrm{~S}-\mathrm{S}-\mathrm{S}-\mathrm{S}-\mathrm{S}$, or $\mathrm{H}_{2} \mathrm{~S} \cdot \mathrm{S}_{x}$. Presumably, therefore, the ions in alkaline solutions are chains such as (S-S-S-S-S $)^{-2}$. Very likely the solubilities reported by KÜSTER and HEBERLEIN are too high since they did not correct for the presence of thiosulfate. As Peschanski and Valensi (1949) and Maronny (1959a) point out there is always some oxidation or disproportionation of polysulfides to form thiosulfate, especially at higher temperatures. Because of this the ratio of the total amount of sulfur (dissolved sulfur plus original sulfide) to original sulfide is higher than $\bar{y}$.

Peschanski and Valensi (1949) have made a rather extensive study of solutions of sodium polysulfides. They equilibrated solutions of $\mathrm{Na}_{2} \mathrm{~S}$ containing various amounts of dissolved $\mathrm{S}$ at $\mathbf{2 5}^{\circ} \mathrm{C}$ and then measured the $\mathrm{pII}$ and $\mathrm{Eh}$ of the solutions. These solutions ranged from those saturated in sulfur to ones with very little $\mathrm{S}$. By measuring the thiosulfate, monosulfide, and polysulfide analytically they avoided the difficulties inherent in the method of KÜsTER and HeberLein (1905). In this way they found that $\bar{y}$ never exceeded $5 \cdot 0$. If they analysed their solutions in the same way as KÜSTER and HEBERLEIN, however, the two sets of measurements were in close agreement. Peschanski and VALEnsI then assumed that no ions such as $\mathrm{S}_{6}{ }^{-2}$, $\mathrm{S}_{7}{ }^{-2}$, or polysulfide ions containing more sulfur existed in aqueous solution, and that the free energy of the reaction, $S_{x}^{-2}+S=S_{x+1}^{-2}$ is a linear function of $x$. The only sulfide and polysulfide species assumed to be present under the experimental conditions were $\mathrm{HS}^{-1}, \mathrm{~S}^{-2}, \mathrm{~S}_{2}^{-2}$, $\mathrm{S}_{3}{ }^{-2}, \mathrm{~S}_{4}{ }^{-2}$, and $\mathrm{S}_{5}{ }^{-2}$. All of the hydropolysulfide ions were assumed to be absent. They then derived standard potentials for a number of oxidation-reduction reactions from the measurements and used these standard potentials to calculate the $\mathrm{pH}, \mathrm{Eh}$, and the concentration of each of the sulfide and polysulfide ions as a function of increasing sulfur content.

The Eh measurements reported by Peschanski and Valensi (1949) agree well with the 
interpolated or extrapolated values obtained in the present study. Their $\mathrm{pH}$ measurements, however, agree poorly, differing in some cases by one $\mathrm{pH}$ unit. Moreover, their values are apparently inconsistent internally, since in some cases the $\mathrm{pH}$ as measured increases with increasing dilution; this is contrary not only to the present measurements but also to their own ealculations. Their use of the old value of $1.2 \times 10^{-15}$ of KNox (1908) for the second dissociation constant of hydrogen sulfide has little effect except to change the ratio of $\left[\mathrm{HS}^{-1}\right]:\left[\mathrm{S}^{-2}\right]$, but not their sum, and to give too high a $\mathrm{pH}$ value in their calculations.

Maronyy $(1959 \mathrm{a}, \mathrm{b})$ and Maronny and Valexsi $(1955,1958,1959)$ have made additional measurements of the potentials in this system and have adjusted the standard potentials and standard free energies of formation of $\mathrm{s}_{2}^{-2}, \mathrm{~s}_{3}^{-2}, \mathrm{~s}_{4}^{-2}$, and $\mathrm{s}_{5}^{-2}$ previonsly estimated by Peschanski and Vatensi (1949).

ARnTSOn, Dickson, and TunExx (1958) have measured the solubility of $\mathrm{S}$ in $\mathrm{Na}_{2} \mathrm{~S}^{2}$ solutions. They analysed the resultant solutions and reported their results as weight percentages of $\mathrm{s}$, $\mathrm{H}_{2} \mathrm{O}$, and $\mathrm{Na}_{2} \mathrm{~S}$. They did not determine thiosulfate. Therefore, as mentioned above in connection with the work of KUSTER and HEBERLEIN (1905) the ratio of total $S$ to original sulfide is probably higher than $\bar{y}$. Some of their values for the ratio at $50^{\circ} \mathrm{C}$ are considerably greater than $\tilde{5} \cdot 0$; this is probably due to marked disproportionation to thiosulfate and hydrosulfide.

In a more recent paper Arsston, Dickson and TUnenL (1960) report the results of solubility measurements of $\mathrm{S}$ in $\mathrm{NaOH}$ solutions at $25^{\circ} \mathrm{C}$. In interpreting their results they assume that $\mathrm{Na}_{2} \mathrm{~S}$ solutions saturated in $\mathrm{S}$ do not disproportionate greatly. At $25 \mathrm{C}$ this appears to be nearly enough correct so as not to affect their conclusions. They found, using this assumption, that their data correspond very closely to the reaction, $(2 x+2) \mathrm{S}+6 \mathrm{NaOH}=2 \mathrm{Na}_{2} \mathrm{~S}_{x}+$ $\mathrm{Na}_{2} \mathrm{~S}_{2} \mathrm{O}_{3}+3 \mathrm{H}_{2} \mathrm{O}$.

\section{Work with hydrogen polysulfides or sulfanes}

FEHÉR and co-workers have made an extensive study of the nature of hydrogen polysulfides. By using special preparation techniques and fractional distillation they have succeeded in separating as pure substances the compounds $\mathrm{H}_{2} \mathrm{~S}_{2}$ through $\mathrm{H}_{2} \mathrm{~S}_{8}$. The purity of the substances was verified by careful investigations of the compositions, of the Raman spectra, and of the osmotic pressures (summarized in FEHÉR et al., 1956, and in FEHÉR and WINKHAUS, 1956). By studying the molar refractivities and densities of these compounds and of the erystalline alkali polysulfides they concluded that polysulfides form only as chain structures, such as H-S-S-S-S-S-H (FehÉr and Berthoud, 1953b, c, 1954; Fehér and NAUSED, 1956; FehÉr, LAUE and WINKHAUS, 1957).

FFH'́ and RAudter (1949) found by using Raman spectra that when sodium pentasulfide solution was decomposed by cold concentrated hydrochloric acid the persulfide oil which was produced contained only $\mathrm{H}_{2} \mathrm{~S}_{4}, \mathrm{H}_{2} \mathrm{~S}_{5}$, and $\mathrm{H}_{2} \mathrm{~S}_{6}$. By using solutions containing less $\mathrm{S}$, such as $\mathrm{Na}_{2} \mathrm{~S}_{2}$, they did not obtain oils containing $\mathrm{H}_{2} \mathrm{~S}_{2}$ or $\mathrm{H}_{2} \mathrm{~S}_{3}$. The proportion of $\mathrm{H}_{2} \mathrm{~S}_{4}$ increased and those of $\mathrm{H}_{2} \mathrm{~S}_{5}$ and $\mathrm{H}_{2} \mathrm{~S}_{6}$ decreased as $\mathrm{S}$ decreased. Apparently the production of the persulfide oil involves some change in the chain length. Thus with $\vec{y}$ of 4.5 in the sodium polysulfide solution $\left(\mathrm{Na}_{2} \mathrm{~S}_{4 \cdot 5}\right)$ the oily acid produced has a $\bar{y}$ of $5 \cdot 5$. Part of this increase could be due to simple loss of sulfide as $\mathrm{H}_{2} \mathrm{~s}$. By considering the facts that the maximum $\bar{y}$ in aqueous polysulfide solutions is 5, that no molecular $S$ is present in the persulfide oil, and that essentially all of the sulfide in a $\mathrm{Na}_{2} \mathrm{~S}$ solution saturated in sulfur is bound to $\mathrm{S}$, forming polysulfides, it becomes evident that the ratio of sulfur to sulfide in the polysulfide chains themselves has incroased. This could take place by some such reaction as

$$
\mathrm{H}_{2} \mathrm{~S}_{4} \text { (liq.) }+\mathrm{H}_{2^{\prime}} \mathrm{S}_{5} \text { (liq.) }-\mathrm{H}_{2} \mathrm{~S}_{8} \text { (liq.) }+\mathrm{H}_{2} \mathrm{~S} \text { (gas) }
$$

If a sodium polysulfide solution with a $\bar{y}$ of 1.5 is used the persulfide has a $\bar{y}$ of $4 \cdot 5$. In this case it is possible that the entire change could be due to simple loss of $\mathrm{H}_{2} \mathrm{~S}$ according to the equation.

$$
2 \mathrm{H}^{+1}+\mathrm{S}^{-2}=\mathrm{H}_{2} \mathrm{~S} \text { (gas) }
$$

Probably there is some contribution from the other type of reaction, however. 


\section{Standard potential of the $\dot{A g} / \mathrm{Ag}_{2} S$ electrode and the free energy of formation of acanthite}

Work by NoDDACK and WrABETz (1955) has shown that the $S$ content of silver sulfide affects the potential of the $\mathrm{Ag} / \mathrm{Ag}_{2} \mathrm{~S}$ electrode. Thus they found that silver sulfide which contained considerable amounts of excess $S$ in solid solution gave potentials differing by as much as $50 \mathrm{mv}$ from silver sulfide with no excess S. Any one electrode, however, gave reproducible potentials and did not drift with time. The significance of this observation for the present work is that, once any given $\mathrm{Ag} / \mathrm{Ag}_{2} \mathrm{~S}$ electrode has been standardized in a solution of known activity of sulfide ion, it can be used with confidence to determine $\left(\mathrm{S}^{-2}\right)$ in an unknown solution. An unstandardized electrode, however, may give erroneous results.

Goates et al. (1951) determined the free energy of silver sulfide from potentiometric measurements. They obtained $-9.562 \mathrm{kcal} / \mathrm{mole}$ for the free energy of formation of $\mathrm{Ag}_{2} \mathrm{~S}$ as compared to the value of $-9.62 \mathrm{kcal} /$ mole reported by Latimer (1952). The $E^{\circ}$ given by GOATES et al., for the reaction $2 \mathrm{Ag}^{+1}+\mathrm{S}^{-2}=\mathrm{Ag}_{2} \mathrm{~S}+2 e^{-1}$ is based on an assumed second dissociation constant of $\mathrm{H}_{2} \mathrm{~S}$ of $1 \times 10^{-15}$. Using instead $\mathrm{p} K_{2}=13.50$ and their free energy value, the $E^{\circ}$ becomes $-0.6732 \mathrm{~V}$.

SAто (1959) has measured the potentials of a number of sulfide electrodes. From the potential of the reduction reaction of silver sulfide in acid solution,

$$
2 \mathrm{Ag}+\mathrm{H}_{2} \mathrm{~S}=\mathrm{Ag}_{2} \mathrm{~S}+2 \mathrm{H}^{+1}+2 e^{-\mathrm{I}},
$$

he obtained $-9 \cdot 36 \mathrm{kcal} /$ mole for the free energy of formation of $\mathrm{Ag}_{2} \mathrm{~S}$. Using this figure and $\mathrm{p} K_{2}=13 \cdot 50$, the standard potential for the reaction $2 \mathrm{Ag}+\mathrm{S}^{-2}=\mathrm{Ag}_{2} \mathrm{~S}+2 e^{-1}$ was calculated as $-0 \cdot 6674 \mathrm{~V}$.

\section{Activity coefficients}

Because of the rather strong solutions used in this investigation the choice of activity coefficients became important. The problems involved have been summarized by HARNED and OWEN (1958).

\section{Equilibrium condition in alkaliz polysulfide solutions}

In all of the work with polysulfides described above as well as in the present study, true equilibrium was not attained. This is due to the fact that the reactions,

$$
4 \mathrm{~S}_{x}^{-2}+4(x-2) \mathrm{OH}^{-1}+(5-x) \mathrm{H}_{2} \mathrm{O}=2(x+1) \mathrm{HS}^{-1}+(x-1) \mathrm{S}_{2} \mathrm{O}_{3}{ }^{-2} \text {, }
$$

should proceed quantitatively to the right in alkaline solution if $x>1$. Using the free energy value derived in this paper the equilibrium constant using $S_{5}^{-2}$ ion is approximately $6 \times 10^{52}$. The free energy value given by MARONNY $(1959 \mathrm{~b}$ ) yields approximately the same constant. At the measured $\mathrm{pH}$. for a sodium sulfide solution $1 \mathrm{M}$ in sodium ion and saturated with sulfur this implies a ratio of thiosulfate to pentasulfide of about $10^{13}$. The actual ratio obtained in the present study was about 0.07 . As is evident from the $\mathrm{Eh}-\mathrm{pH}$ diagram for $\mathrm{S}$ (ef. VALENsr, 1951 or GARRELS and NAESER, 1958), the thiosulfate should disproportionate also to give sulfide and sulfatc.

\section{Apparatus}

The measurements of potentials were made with commercial $\mathrm{pH}$ and mv meters and recorded every $18 \mathrm{sec}$ on a multi-record potentiometer. The instruments were carefully adjusted to measure $\mathrm{pH}$ to \pm 0.02 units and potentials to \pm 2 millivolts. Measurements were made with high pH glass electrodes (Beckman type E-2) rated as having no appreciable sodium ion error, thimble style platinum electrodes, and billet style silver-silver sulfide electrodes against sleeve type saturated calomel electrodes. The glass electrodes were standardized with $\mathrm{pH} 7$ and $\mathrm{pH} 9$ buffers, and occasionally with pH 4 buffer as well. The platinum electrode potential was cheeked against Zobell solution (ZUBELL, 1946) which gives an $\mathrm{Eh}$ of $0.430 \mathrm{~V}$ at $25^{\circ} \mathrm{C}$ when freshly prepared. The $\mathrm{Ag} / \mathrm{Ag}_{2} \mathrm{~S}$ electrode was prepared from a silver billet electrode by electrolysis in carefully prepared dilute $\mathrm{Na}_{2} \mathrm{~S}$ solution. The electrolysis was done with low current density for about twice as long as was required for the surface to become a uniform black. This electrode 
was standardized against $\mathrm{Na}_{2} \mathrm{~S}$ solutions of known strength and periodically re-checked. The potentials were reproducible within a few mv for more than 12 months.

The solutions were placed in Pyrex containers of about $500 \mathrm{ml}$ capacity with a flanged top, which was ground flat. The container was covered with a Plexiglas plate perforated with holes to fit rubber stoppers and sealed to the glass with beeswax or with silicone grease. The electrodes were led into the container through rubber stoppers which were tightly wedged into the holes. The solution was stirred by a teflon-coated magnetic bar and a magnetic stirrer. To prevent conversion of the calomel to mercuric sulfide and mercury by diffusing sulfide ions the calomel electrodes were generally placed in a second identical container and the two connected by a salt bridge containing $1 \mathrm{MNaNO}_{3}$. The junctions were made by means of vory fincly drawn capillaries such that the flow of solution was no more than $1 \mathrm{ml} /$ day and arranged so that the solution always flowed into the polysulfide container. To guarantee that no junction potentials arose in this way the calomel electrodes were occasionally transferred to the polysulfide container for short periods and the cell potentials measured.

A separate platinum electrode was used for a solution ground for each of the three meters. In addition a thermocompensator (resistance thermometer) was immersed in the solution and connected to the $\mathrm{pH}$ meter. There were thus six electrodes, a thermocompensator, a thermom. eter, and one end of the salt bridge in the polysulfide container, and three calomel electrodes and the other end of the salt bridge in the other container. The second container was filled by $1 \mathrm{M}$ $\mathrm{NaNO}_{3}$ solution.

\section{Expertmental Methods}

\section{Preparation of $\mathrm{Na}_{2} \mathrm{~S}$ solutions}

Stock solutions of $\mathrm{Na}_{2} \mathrm{~S}$ were prepared by dissolving clear washed crystals of $\mathrm{Na}_{2} \mathrm{~S} \cdot 9 \mathrm{H}_{2} \mathrm{O}$ (any yellow portions were discarded) in distilled water treated for two hours by rapidly flowing nitrogen. The nitrogen was obtained from commercial tanks and passed through a $\mathrm{CO}_{2}$ absorbent, next through either a solution containing $\mathrm{V}^{+2}$ and $\mathrm{V}^{+3}$ (maintained in a reduced condition by amalgamated $\mathrm{Zn}$ and dilute $\mathrm{H}_{2} \mathrm{SO}_{4}$ ) or through copper turnings at $400^{\circ} \mathrm{C}$ to remove $\mathrm{O}_{2}$, and finally through distilled water. This $\mathrm{Na}_{2} \mathrm{~S}$ solution was analysed for total $\mathrm{S}$, thiosulfate, and sulfide.

\section{Analysis of sulfide solutions}

Total $\mathrm{S}$ was determined by either of two methods. In the first a slight oxecss of sodium hydroxide was added to an aliquot of the sulfide or polysulfide solution, and all sulfur species were oxidized to sulfate by an excess of $\mathrm{H}_{2} \mathrm{O}_{2}$. The solution was boiled to remove the excess peroxide, acidified by $\mathrm{HCl}$, and the sulfate precipitated and weighed as barium sulfate. Tater in the exporimental work total $\mathbf{S}$ was determined by adding an aliquot of the sulfide or polysulfide to a measured excess of standard $\mathrm{NaOH}$, and oxidizing by $\mathrm{H}_{2} \mathrm{O}_{2}$. The excess of hydroxide was then back titrated by standard $\mathrm{HCl}$ or $\mathrm{H}_{2} \mathrm{SO}_{4}$ after the method of FeHÉr and BERTHOLD (1953a).

Thiosulfate was found by adding an aliquot to an excess of zinc acetate solution, filtering, acidifying by acetic acid, and titrating with iodine. The amount of $S$ as thiosulfate was always less than 0.1 per cent of the total $\mathrm{S}$. The amount of monosulfide was determined by adding an aliquot to an excess of acidified iodine solution, and back titrating with standard thiosulfate.

The total $\mathrm{S}$ estimated from the sum of that present as sulfide and thiosulfate in the $\mathrm{Na}_{2} \mathrm{~S}$ solutions (without excess $\mathrm{S}$ ) agreed with the amount found by either direct method for total $\mathrm{S}$.

\section{Experiments with polysulfide solutions}

In one set of experiments weighed amounts of flowers of sulfur were placed in polyethylene flasks and the air displaced by nitrogen. Then an aliquot of the stock solution of $\mathrm{Na}_{2} \mathrm{~s}$, pipetted under a nitrogen atmosphere, and $10 \mathrm{ml}$ of a suspension of $\mathrm{N}_{2}$-treated distilled water and carefully precipitated acanthite* were added. Finally enough nitrogen-treated distilled water was added to dilute the sulfide to some desired strength. After stirring for 24 to $100 \mathrm{hr}$ with a teflon coated bar and the magnetic stirrer, the solutions were transferred to an electrode container, either completely under a $\mathrm{N}_{2}$ atmosphere or by pouring rapidly through a funnel while a $\mathrm{N}_{2}$

\footnotetext{
* The solubilities of acanthite in these solutions will be reported in a separate paper.
} 
stream was played over the surface of the liquid. The electrode potentials were then measured. Both methods of transfer gave identical potential readings.

A second set of experiments was performed by adding the constituents directly to the electrode container. In this set the starting solutions were either standard $\mathrm{NaOH}$, carbonate and oxygen free, or $\mathrm{Na}_{2} \mathrm{~S}$. As before $\mathrm{S}, \mathrm{H}_{2} \mathrm{O}$, and acanthite were added. In addition $\mathrm{H}_{2} \mathrm{~S}$ from a Kipp's generator was bubbled slowly through the solution. The supply of $\mathrm{H}_{2} \mathrm{~S}$ was either continued to saturation or stopped at some desired intermediate point. The potentials were recorded every $18 \mathrm{sec}$ throughout the experiment. The $\mathrm{H}_{2} \mathrm{~S}$ was generated from sticks of ferrous sulfide in a $\mathrm{N}_{2}$ atmosphere by $\mathrm{N}_{2}$-treated $\mathrm{H}_{2} \mathrm{SO}_{4}$. The reducing effect of the $\mathrm{H}_{2}$, doubtless produced from unsulfidized metallic iron, did not seem to affect the Eh in 2 days time. Hydrogen sulfide from commercial tanks was found to contain oxidizing substances which were not readily removed.

The solutions from both types of experiments were analyzed as above for total s, monosulfide, and thiosulfate. Since thiosulfate was always negligible, however, some of the solutions were not analysed for total $S$ and monosulfide, but these quantities were calculated from the initial amounts of $\mathrm{S}$ and $\mathrm{Na}_{2} \mathrm{~S}$.

\section{Experimental Results}

The measured data are presented in Tables 1, 2, and 3, or are shown graphically in Figs. 1 and 2. Most of the $\mathrm{Ag} / \mathrm{Ag}_{2} \mathrm{~S}$ electrode potentials in Table 1 (and a few

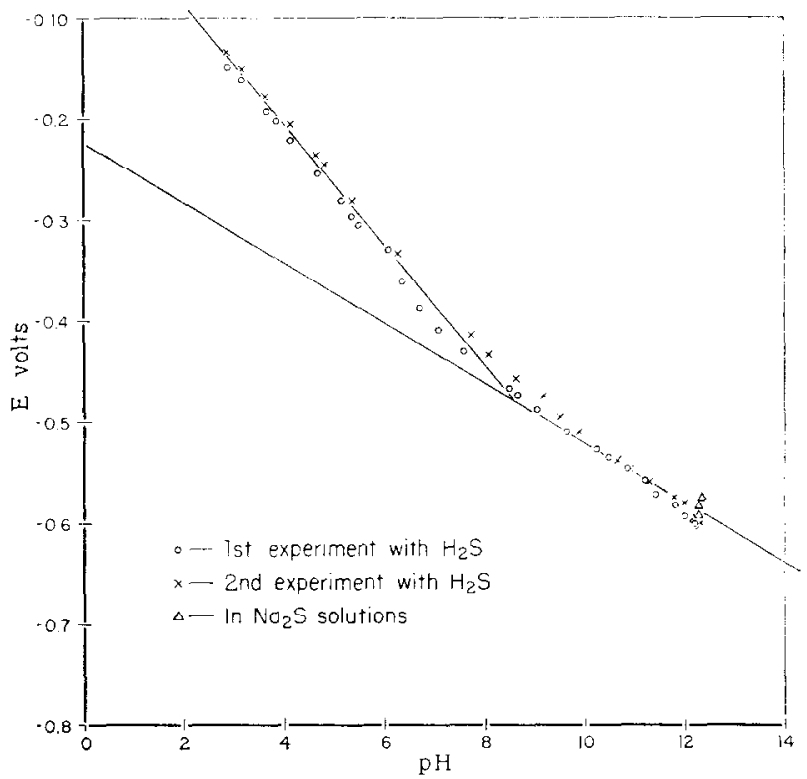

Fig. 1. Measured values of the potentials of the $\mathrm{Ag} / \mathrm{Ag}_{2} \mathrm{~S}$ electrode vs. standard $\mathrm{H}_{2}$ electrode for sulfide solutions $0.0900 \mathrm{M}$ in $\mathrm{Na}^{+1}$.

others) are also plotted in Fig. 3 against the neg. log of sulfide activity (calculated). The temperature was maintained at approximately $30^{\circ} \mathrm{C}$ by the heat generated from the motor in the stirrer.

\section{Eh-pH values in sodium polysulfide solutions}

The Eh and $\mathrm{pH}$ values are plotted against $\bar{y}$ in Fig. 4 for solutions $1 \mathrm{M}$ in $\mathrm{Na}^{+1}$. The solid curves were calculated according to the model derived later in this paper, 
Table 1. Measurements with no $\mathrm{S}$ added (cf. also Figs. 1 and 2)

\begin{tabular}{|c|c|c|c|c|}
\hline $\begin{array}{l}\text { Moles } \\
\mathrm{Na}^{+1} / \mathrm{l} .\end{array}$ & $\mathrm{pH}$ & $\begin{array}{c}E \text { of } \mathrm{Ag} / \mathrm{Ag}_{2} \mathrm{~S}-\mathrm{H}_{2} \\
\text { couple, } \mathrm{V}\end{array}$ & Eh, V & $t^{\circ} \mathrm{C}$ \\
\hline 1.000 & $13 \cdot 20$ & -0.655 (low) & & 30 \\
\hline 1.000 & $12 \cdot 80$ & -0.639 (low) & $-0 \cdot 490$ & $30 \cdot 0$ \\
\hline $0 \cdot 666$ & $12 \cdot 64^{*}$ & -0.615 & $-0 \cdot 344^{*}$ & 25 \\
\hline $0 \cdot 370_{4}$ & 12.90 & -0.607 & $-0 \cdot 359$ & 25 \\
\hline $0 \cdot 256_{6}$ & $12 \cdot 80$ & -0.604 & $\begin{array}{c}-0.349 \text { drifts to } \\
-0.324\end{array}$ & 25 \\
\hline $0 \cdot 183_{4}$ & $12 \cdot 66$ & & $-0 \cdot 442$ & 25 \\
\hline $0.177_{6}$ & $12 \cdot 68$ & $-0 \cdot 590$ & -0.321 & 25 \\
\hline $0.124_{0}$ & & & $-0 \cdot 474$ & 25 \\
\hline $0 \cdot 1004$ & $12 \cdot 09$ & -0.582 & -0.421 & $29 \cdot 0$ \\
\hline $0 \cdot 0986$ & $12 \cdot 50$ & $-0 \cdot 589$ & -0.312 & 25 \\
\hline $0 \cdot 0900$ & $12 \cdot 32$ & -0.584 & & 25 \\
\hline 0.0683 & $12 \cdot 38$ & -0.582 & -0.310 & 25 \\
\hline 0.0380 & $12 \cdot 15$ & -0.562 & -0.291 & 25 \\
\hline 0.0262 & $12 \cdot 01$ & -0.558 & -0.289 & 25 \\
\hline 0.0180 & $11 \cdot 78$ & $-0 \cdot 544$ & & 25 \\
\hline 0.0180 & $11 \cdot 86$ & -0.540 & & 25 \\
\hline 0.0180 & & -0.542 & & 25 \\
\hline
\end{tabular}

* Electrodes probably not immersed deeply enough.

Table 2. Measurements with $\mathrm{S}$ added to $\mathrm{Na}_{2} \mathrm{~S}$ solutions with no addition of $\mathrm{H}_{2} \mathrm{~S}$.

\begin{tabular}{|c|c|c|c|c|c|c|}
\hline $\begin{array}{l}\text { Moles } \\
\mathrm{Na}^{+1} / \mathrm{l}\end{array}$ & $\mathrm{pH}$ & $\begin{array}{c}E \text { of } \mathrm{Ag} / \mathrm{Ag}_{2} \mathrm{~S}-\mathrm{H}_{2} \\
\text { couple, } \mathrm{V}\end{array}$ & $\mathrm{Eh}, \mathrm{V}$ & $\ddot{y}$ & $\begin{array}{l}\mathrm{S}_{2} \mathrm{O}_{3}{ }^{-2} \\
\text { moles/1. }\end{array}$ & $t^{\circ} \mathrm{C}$ \\
\hline $1.000^{*}$ & 12.95 & -0.638 & & 1.5 & & 25 \\
\hline 1.000 & $12 \cdot 86$ & -0.607 & -0.466 & $2 \cdot 0$ & 0.023 & 31.5 \\
\hline $1.000^{*}$ & $12 \cdot 50$ & -0.625 & & $2 \cdot 0$ & & 30 \\
\hline $1 \cdot 000$ & $12 \cdot 88$ & $-0 \cdot 615$ & $-0 \cdot 442$ & $3 \cdot 0$ & 0.010 & $30 \cdot 0$ \\
\hline $1 \cdot 000$ & $12 \cdot 55$ & $-0 \cdot 600$ & -0.437 & $3 \cdot 0$ & 0.011 & 30 \\
\hline $1 \cdot 000^{*}$ & $12 \cdot 28$ & $-0 \cdot 607$ & & $3 \cdot 0$ & & 30 \\
\hline $1 \cdot 000$ & $12 \cdot 50$ & -0.582 & -0.420 & $3 \cdot 5$ & 0.015 & $32 \cdot 8$ \\
\hline 1.000 & $12 \cdot 28$ & -0.567 & -0.401 & $4 \cdot 0$ & $0 \cdot 007$ & 30 \\
\hline 1.000 & $12 \cdot 37$ & -0.571 & -0.401 & 4.0 & $0 \cdot 007$ & 30 \\
\hline 1.000 & $12 \cdot 20$ & -0.575 & -0.400 & 4.0 & 0.009 & $30 \cdot 5$ \\
\hline $1.000^{*}$ & 11.90 & -0.571 & & $4 \cdot 0$ & & 30 \\
\hline 1.000 & $11 \cdot 75$ & -0.517 & -0.353 & $4 \cdot 5$ & 0.011 & $30 \cdot 5$ \\
\hline $1 \cdot 000$ & $11 \cdot 34$ & -0.502 & -0.316 & 4.9 & 0.004 & $31 \cdot 0$ \\
\hline $1 \cdot 000$ & $11 \cdot 00$ & -0.491 & -0.310 & 4.9 & $0 \cdot 023$ & $30 \cdot 5$ \\
\hline 1.000 & $11 \cdot 25$ & -0.505 & -0.317 & $4 \cdot 9$ & & 30 \\
\hline $1 \cdot 000 *$ & $11 \cdot 37$ & -0.522 & & $4 \cdot 9$ & 0.004 & 30 \\
\hline $0 \cdot 600$ & $12 \cdot 50$ & -0.589 & -0.443 & $2 \cdot 5$ & 0.008 & $33 \cdot 5$ \\
\hline $0 \cdot 600$ & $12 \cdot 35$ & -0.582 & $-0 \cdot 436$ & $3 \cdot 0$ & 0.010 & $34+5$ \\
\hline 0.600 & $11 \cdot 80$ & -0.549 & $-0 \cdot 388$ & $4 \cdot 0$ & $0 \cdot 006$ & 34.8 \\
\hline 0.600 & $10 \cdot 33$ & -0.480 & $-0 \cdot 302$ & $4: 9$ & $0 \cdot 006$ & $35 \cdot 0$ \\
\hline 0.200 & $12 \cdot 05$ & -0.553 & -0.406 & $3 \cdot 0$ & 0.006 & $32 \cdot 0$ \\
\hline 0.200 & $11 \cdot 53$ & $-0 \cdot 498$ & -0.364 & $4 \cdot 0$ & $0 \cdot 006$ & $32 \cdot 5$ \\
\hline 0.200 & $11 \cdot 50$ & $0 \cdot 513$ & -0.364 & 40 & 0.008 & $33 \cdot 5$ \\
\hline $0 \cdot 200$ & $10 \cdot 50$ & -0.462 & -0.298 & $4 \cdot 9$ & 0.004 & $32 \cdot 0$ \\
\hline
\end{tabular}

* These 5 sets of values derived from one experiment with successive additions of $s ;$ the entire set appears to give incorrect $\mathrm{pH}$ and/or $\mathrm{pS}$ values. 


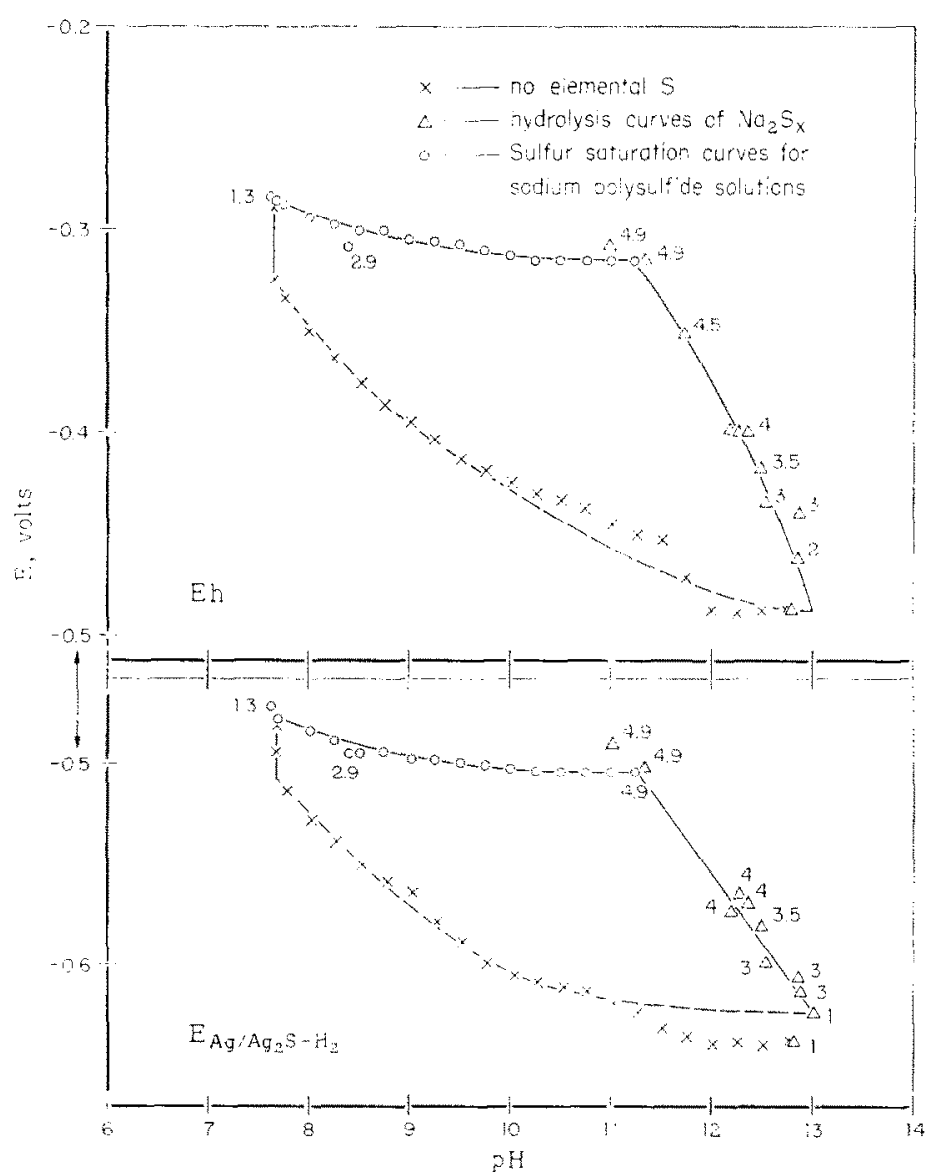

Fig. 2. Measured values of the potentials of the $\mathrm{Ag} / \mathrm{Ag}_{2} \mathrm{~S}$ (lower set of curves) and smooth $\mathrm{Pt}$ (upper set) electrodes vs. standard $\mathrm{H}_{2}$ electrode for sulfide and poly. sulfide solutions $1.0 \mathrm{M}$ in $\mathrm{Na}^{+1}$. Numbers indicate the $\bar{y}$ of the solutions.

Table 3. Measurements with addition of $\mathrm{H}_{2} \mathrm{~S}$ and saturated in $\mathrm{S}$ (cf. also Fig. 2)

\begin{tabular}{|c|c|c|c|c|c|c|}
\hline $\begin{array}{l}\text { Woles } \\
\mathrm{Na}^{+1} / 1\end{array}$ & $\mathrm{pH}$ & $\begin{array}{c}E \text { of } \mathrm{Ag} / \mathrm{Ag}_{2} \mathrm{~S}-\mathrm{H}_{2} \\
\text { couple, } \mathrm{V}\end{array}$ & Eh, V & $\vec{y}$ & $\begin{array}{l}\mathrm{S}_{2} \mathrm{O}_{3}^{-2} \\
\text { moles/1. }\end{array}$ & $i^{\circ} \mathrm{C}$ \\
\hline $1.000 *$ & $7 \cdot 65$ & -0.478 & $-0 \cdot 286$ & $1 \cdot 3$ & 0.004 & $30 \cdot 0$ \\
\hline $1.000^{*}$ & $7 \cdot 62$ & -0.473 & -0.284 & $1 \cdot 3$ & 0.013 & 25 \\
\hline $1.000 *$ & $7 \cdot 69$ & -0.482 & -0.289 & $1 \cdot 3$ & 0.002 & $28 \cdot 0$ \\
\hline 1.000 & $8 \cdot 40$ & -0.495 & $-0 \cdot 309$ & $2 \cdot 9$ & 0.007 & 30 \\
\hline $1 \cdot 000$ & $11 \cdot 98$ & -0.589 & -0.429 & $3 \cdot 3 \dagger$ & & 30 \\
\hline $0.100 *$ & $6 \cdot 88$ & -0.429 & $-0 \cdot 248$ & 1.03 & $0 \cdot 0006$ & 25 \\
\hline $0 \cdot 100 *$ & 6.92 & -0.424 & $-0 \cdot 247$ & $1 \cdot 01$ & 0.0005 & $29 \cdot 5$ \\
\hline
\end{tabular}

* Saturated in $\mathrm{H}_{2} \mathrm{~S}$.

$\uparrow$ Not saturated in $\mathrm{S}$. 
and the dashed lines were taken from the calculated curves of Peschanski and VALENSI (1949).

$p H$ values in $\mathrm{Na}_{2} \mathrm{~S}$ solutions

In Fig. 5 the $\mathrm{Na}_{2} \mathrm{~S}$ hydrolysis $\mathrm{pH}$ values measured in this set of experiments are plotted. For comparison the pH's from the work of KonopIK and LererL (1949) and of Kubli (1946) are also represented. The solid line shows pH's calculated as

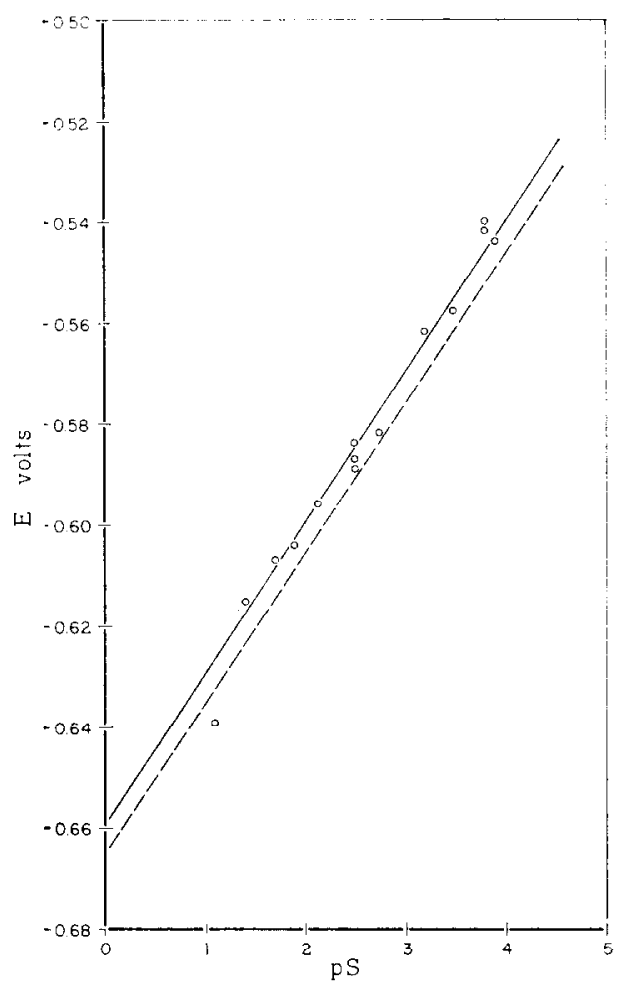

Fig. 3. Plot of $\mathrm{pS}$ vs. measured potentials of the $\mathrm{Ag} / \mathrm{Ag}_{2} \mathrm{~S}$ electrode for $\mathrm{Na}_{2} \mathrm{~S}$ solutions of various concentrations.

described under the section dealing with activity coefficients. All data were recalculated to $25^{\circ} \mathrm{C}$.

Temperature corrections

Recalculation to $25^{\circ} \mathrm{C}$ was done using the equation:

$$
\left(\mathrm{H}^{+1}\right)=\left\{K_{W}+\sqrt{K_{W}^{2}+4 K_{2} K_{W} c \gamma_{\mathrm{OH}^{-1}}^{2} / \gamma_{\mathrm{S}^{-2}}}\right\} / 2 c \gamma_{\mathrm{OH}^{-1}}
$$

The activity coefficient of $\mathrm{HS}^{-1}$ is taken as equal to that of $\mathrm{OH}^{-1}$. Equation (1) was derived from the relations:

and

$$
\begin{aligned}
K_{2} & =\left(\mathrm{H}^{+1}\right)\left(\mathrm{S}^{-2}\right) /\left(\mathrm{HS}^{-}\right) & K_{w} & =\left(\mathrm{H}^{+1}\right)\left(\mathrm{OH}^{-1}\right) \\
c & =\left[\mathrm{S}^{-2}\right]+\left[\mathrm{HS}^{-1}\right] & \gamma_{\mathrm{OH}^{-1}}\left[\mathrm{OH}^{1}\right] & =\left(\mathrm{OH}^{1}\right) \\
\gamma_{\mathrm{HS}^{-1}}\left[\mathrm{HS}^{-1}\right] & =\left(\mathrm{HS}^{-1}\right) & \gamma_{\mathrm{S}^{-2}}\left[\mathrm{~S}^{-2}\right] & =\left(\mathrm{S}^{-2}\right)
\end{aligned}
$$


'The last expression is a consequence of the hydrolysis reaction

$$
\mathrm{H}_{2} \mathrm{O}+\mathrm{S}^{-2}=\mathrm{HS}^{-1}+\mathrm{OH}^{-1}
$$

in which equal amounts of hydroxide and hydrosulfide are produced. By dividing both sides of Equation (1) by $K_{2}$ an expression is obtained in which the right hand

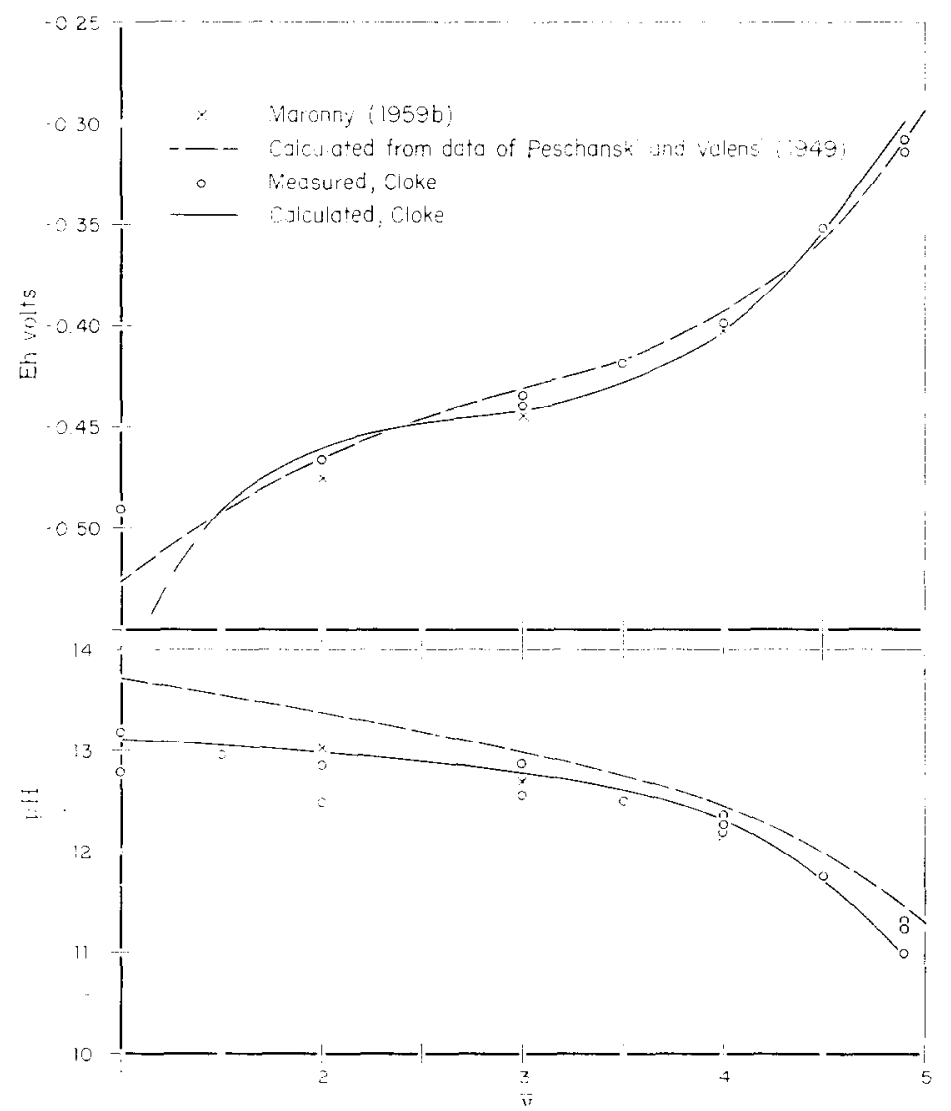

Fig. 4. Redox potential (Eh) and $\mathrm{pH}$ of $\mathrm{Na}_{2} \mathrm{~S}_{x}$ solutions $\mathrm{I} \cdot 0 \mathrm{M}$ in $\mathrm{Na}^{+1}$.

member is practically constant since the ratio $K_{w} / K_{2}$ and the $\gamma$ 's change only very slowly with temperature. Writing:

$$
\left(\mathrm{H}^{+1}\right) / K_{2}=f(c),
$$

where $f(c)$ is a function of concentration only, taking logs, and differentiating with respect to temperature, there results:

$$
\left[d \ln \left(\mathrm{H}^{+1}\right)\right] / d T=\left(d \ln K_{2}\right) / d T
$$

i.e. the change of $\mathrm{pH}$ with temperature is given closely by the change in $\mathrm{p} K_{2}$. For a $5^{\circ}$ temperature interval this is about $0 \cdot 15 \mathrm{pH}$ units. 
Comparison of results of polysulfide studies with previous work

The agreement of the Eh values for polysulfide solutions (Fig. 4) with those given by Peschanski and Valensi (1949) is reasonably good, and except for points at $\bar{y}=1$ the experimental measurements fall quite close to the curves. Theoretically at $\bar{y}=1$ there should be no polysulfide species and the Eh should be very strongly negative. It would be limited only by the water-hydrogen couple, or determined by couples involving other species, such as thiosulfate. Presumably the wide

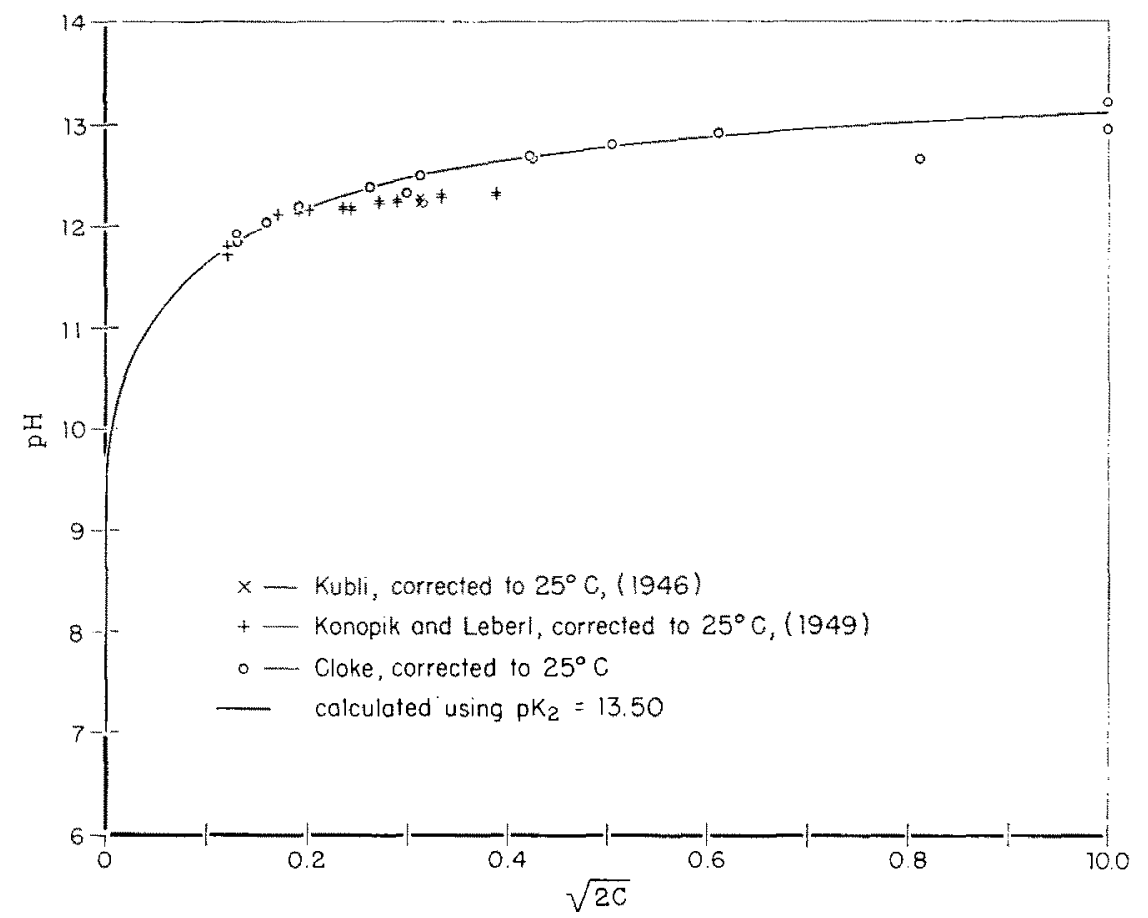

Fig. 5. Measured and calculated $\mathrm{pH}$ vs. $\sqrt{\left[\mathrm{Na}^{+1}\right]}$ for $\mathrm{Na}_{2} \mathrm{~S}$ solutions. $\sqrt{\left[\mathrm{Na}^{+1}\right]}$ is approximately the ionic strength for much of the graph.

variation in measured Eh values at very low $\bar{y}$ is due to small changes in the activities of these other species.

The agreement of $\mathrm{pH}$ values for polysulfide solutions calculated in this paper with those calculated by Peschanski and Valensi (1949) is quite poor. However, the measured $\mathrm{pH}$ 's as reported in Table 1 correspond well with those calculated here and with the experimental data given by Maronny $(1959 \mathrm{a}, \mathrm{b})$ and by MaronNy and Valensi $(1955,1956,1957,1958,1959)$. The disagreement with Peschanski and VALENSI arises largely from their use of $\mathrm{p} K_{\mathbf{2}}=14 \cdot 90$.

Comparison of results of sulfide studies with previous work

The measured $\mathrm{pH}$ values for $\mathrm{Na}_{2} \mathrm{~S}$ solutions are shown in Fig. 5. The solid line which agrees well with the measurements was calculated using equation (1) with $\mathrm{p} K_{2}=13 \cdot 50$. The activity coefficients for this computation were taken from Fig. 6 using the uppermost curve for $\gamma_{\mathrm{OH}^{-1}}$ and $\gamma_{\mathrm{HS}^{-1}}$ and the upper $\gamma_{\mathrm{S}^{-2}}$ line. 
The $\mathrm{pH}$ values measured here for $\mathrm{Na}_{2} \mathrm{~S}$ solutions differ from the earlier work by 0.1 to $0.3 \mathrm{pH}$ units. It is presumed that the previous work gave low $\mathrm{pH}$ readings. KUBLI (1946) used an ordinary glass electrode and corrected for sodium ion error. At high $\mathrm{pH}$ this sodium ion correction becomes large and uncertain. KoNOPIK and LEBERL (1949) used colorimetric indicators; the precision of this method is less than that using potential measurements, and possible systematic errors in solutions

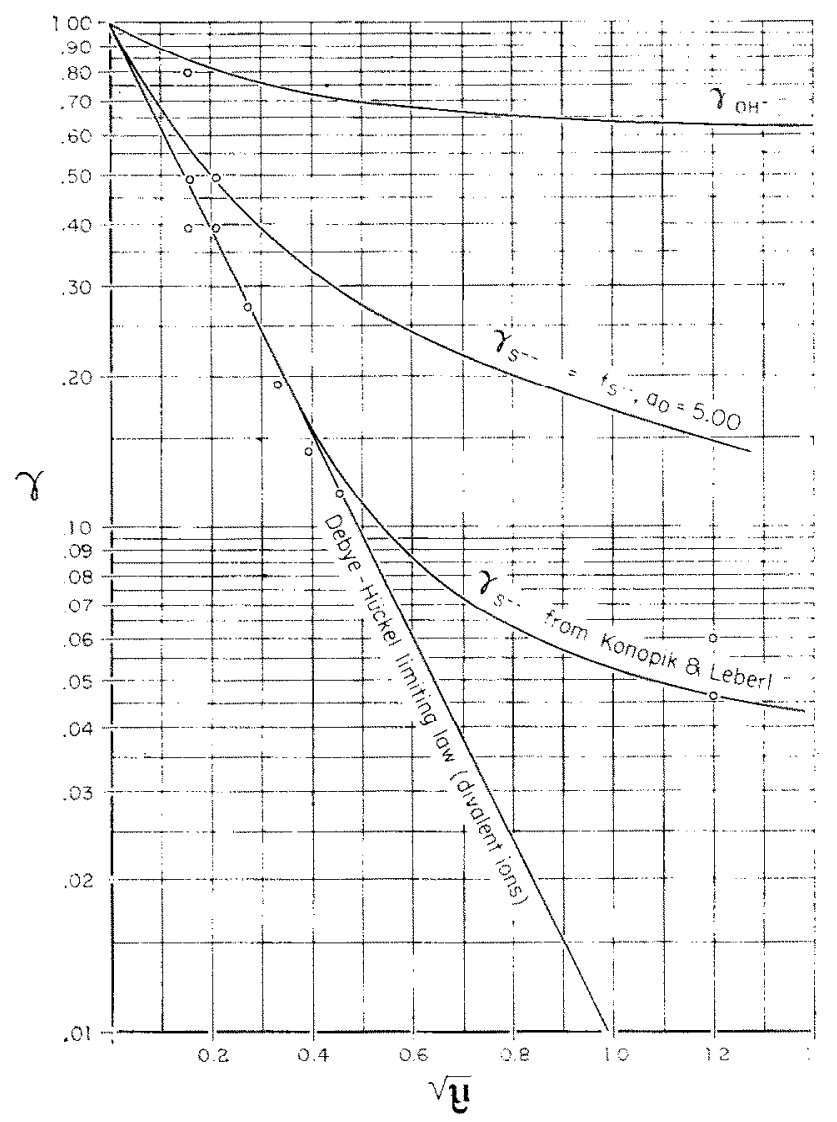

Fig. 6. Activity coefficients for $\mathrm{OH}^{-1}$ or $\mathrm{HS}^{-1}$ and for $\mathrm{S}^{-2}$ plotted on a log scale vs. $\sqrt{\mu}$. The points shown are calculated from $\mathrm{pH}$ measurements made by KoNoPIK and LEBERL (1949), the value of 12.89 for $\mathrm{pK}_{2}$ derived from these measurements by KURY, Zielen, and LATIMER (1953), and the $\gamma_{O H^{-1}}$ curve shown.

containing sulfide ion do not seem to have been thoroughly investigated. A projection of KonOPIK and LEBERL's data to $0.5 \mathrm{M}$ gives a $\mathrm{pH}$ which is considerably lower than the measured values. It seems unlikely that errors in the present data could account for this great a discrepancy at the high concentrations.

\section{Measurements of $\mathrm{Ag} / \mathrm{Ag}_{2} \mathrm{~S}$ electrode potentials}

Measurements of the potential of the $\mathrm{Ag} / \mathrm{Ag}_{2} \mathrm{~S}$ electrode are plotted in Fig. I against the $\mathrm{pH}$ of the solution. Values of the free energy of formation of $\mathrm{Ag}_{2} \mathrm{~S}$ may 
be obtained from these measurements. If the line of smaller slope in Fig. 1 is projected with the slope $-0.0295 \mathrm{~V} / \mathrm{pH}$ unit to $\mathrm{pH}=0$, the standard potential for the reaction

$$
2 \mathrm{Ag}+\mathrm{HS}^{-1}=\mathrm{Ag}_{2} \mathrm{~S}+\mathrm{H}^{+1}+2 e^{-1}
$$

is found to be $-0.272 \mathrm{~V}$ (corrected to $25^{\circ} \mathrm{C} ;\left(\mathrm{HS}^{-1}\right.$ ) is estimated at $0.045 \times 0.74$ moles/liter, where $0.045=\left[\mathrm{HS}^{-1}\right]$ and $\left.0.74=\gamma_{\mathrm{HS}^{-1}}\right)$. Taking $\Delta \mathrm{F}_{\mathrm{HS}^{-1}}^{\circ}=3.00 \mathrm{kcal} /$ mole, $\Delta \mathrm{F}_{\mathrm{Ag}_{2} \mathrm{~S}}^{\circ}$ is calculated as $-9.53 \mathrm{kcal} / \mathrm{mole}$, in good agreement with GoATEs et al. (1951).

The line of slope $-0.059 \mathrm{~V} / \mathrm{pH}$ unit in Fig. 1 lies too high, probably because of oxidation of sulfide to $\mathrm{S}$ (the $\mathrm{S}$ was observed) by $\mathrm{H}_{2} \mathrm{SO}_{4}$, and/or loss of $\mathrm{H}_{2} \mathrm{~S}$ to the overlying atmosphere. Consequently it could not be used to obtain a standard potential.

In Fig. 3 the measured potentials are plotted against activity of sulfide ion. This activity is calculated either from the measured $\mathrm{pH}$ or from equation (1) with $\mathrm{p} K_{2}=$ $13 \cdot 50$, and use of the relations

and

$$
\begin{aligned}
\mathrm{pH}+\mathrm{pOH} & =\mathbf{1 4} \cdot 00, \\
\mathrm{pOH} & =\mathrm{pHS},
\end{aligned}
$$

$\mathrm{pH}+\mathrm{pS}-\mathrm{pHS}=13 \cdot 50$

Projecting to $\mathrm{pH}=0$ with the theoretical slope of $0.0295 \mathrm{~V} / \mathrm{pS}$ unit the standard potential for the reaction,

$$
2 \mathrm{Ag}+\mathrm{S}^{-2}=\mathrm{Ag}_{2} \mathrm{~S}+2 e^{-1}
$$

is obtained as $-0.659 \mathrm{~V}$. This corresponds to $\Delta F^{\circ}{ }_{\mathrm{Ag}_{2} \mathrm{~S}}=-9.07 \mathrm{kcal} / \mathrm{mole}$.

The overall agreement of the standard potential of the electrode $\mathrm{Ag} / \mathrm{Ag}_{2} \mathrm{~S}$ with previously determined constants (GoATES et al., 1951; SATO, 1959) indicates that the $\mathrm{Ag} / \mathrm{Ag}_{2} \mathrm{~S}$ electrode is functioning properly and gives reproducible results.

For this electrode the two standardization procedures give slightly different standard potentials. It was, therefore, decided to use the average of the two free energies of formation, namely, $\Delta F^{\circ}{ }_{A_{2}} \mathrm{~s}=-9 \cdot 30 \mathrm{kcal} / \mathrm{mole}$. This gives $E^{\circ}$ for this electrode as $-0.665 \mathrm{~V}$. The corresponding line is dashed in Fig. 3.

\section{Mean salt approach}

\section{Activity Coefficients}

One of the most difficult problems in the interpretation of the data is the proper choice of activity coefficients in the strong solutions used. In the final analysis any choice of activity coefficients which is consistent with the $\mathrm{p} K_{2}$ adopted gives the correct (within experimental error) sum of $\left[\mathrm{HS}^{-1}\right]$ and $\left[\mathrm{S}^{-2}\right]$, and gives equal calculated concentrations of $\mathrm{HS}^{-1}$ and $\mathrm{OH}^{-1}$. For this work these are the only critical factors related to this problem.

Since only the mean ionic activity coefficients of salts can be measured directly, it is necessary to make some assumption as to how to split the activity coefficient of the cation from that of the anion. In dilute solutions this is usually done by assuming that with $\mathrm{KCl}$ the activity coefficient of potassium ion equals that of chloride ion. Activity coefficients of other ions may then be found from the equation 
$\gamma_{+}{ }^{q} \cdot \gamma_{-}{ }^{r}=\gamma_{ \pm}^{q+r}$ by assuming that the $\gamma^{\prime}$ 's for cations are independent of the particular anions present (except for their charge) and vice versa. Thus the activity coefficient for sodium ion may be estimated from the mean ionic activity coefficient of sodium chloride and the activity coefficient of chloride ion as obtained from potassium chloride.

\section{Other approaches}

With more concentrated solutions, however, many types of specific interaction, such as hydration, ion pair formation, change of the dielectric constant etc., become of importance and it becomes questionable whether the mean salt approach gives the proper interpretation (cf. HARNED and OWEN, 1958). To estimate the activity coefficient of hydrosulfide ion, the author has used three different lines of argument, all of which give reasonably consistent answers. Two of these deal mostly with modifications of the mean salt approach, taking into account similarities and differences of the ions involved. The arguments for the activity coefficients of sulfide ion are less satisfactory, but the relation chosen gives results in agreement with experimentally determined $\mathrm{pH}$ values.

(a) Use of similarity of size and charge of $\mathrm{HS}^{-1}$ and $\mathrm{OH}^{-1}$. On the basis of the Debye-Hückel equation it is reasonable to expect hydroxide and hydrosulfide ions to have the same activity coefficients, since they have the same charge and KIELLAND (1937) gives the same $a_{0}$ for both. Probably, however, $\mathrm{OH}^{-1}$ is more hydrated than $\mathrm{HS}^{-1}$. The crystal ionic radius of oxide ion is considerably smaller than that of sulfide ion. If they have the same effective radius in aqueous solution (presumably the addition of the proton will have little effect on the radius) the difference is probably due to water molecules being held more strongly to the hydroxide. According to Robinson and Stokes (1949) this hydration effect should increase the activity coefficient of hydroxide ion, but not of hydrosulfide because the crystal radius of sulfide ion is about the same as the radius of $\mathrm{HS}^{-1}$ as given by KIELLAND (1937).

On the other hand Grvblett and Monk (1954) have concluded that $\mathrm{NaOH}$ is partially associated whereas the hydroxides of potassium, rubidium, and cesium are not (for this purpose ion pair formation, localized hydrolysis etc., may be considered as special types of association). The effect of association is to decrease the stoichiometric activity coefficient. By considering the dissociation constants of $\mathrm{H}_{2} \mathrm{~S}$ and of $\mathrm{H}_{2} \mathrm{O}$ it is seen that the attraction of hydrogen ion for sulfide is weaker than its attraction for oxide. By analogy it may be assumed that the attraction of sodium ion for sulfide is likewise weaker than the attraction of $\mathrm{Na}^{+1}$ for oxide. It follows that $\mathrm{NaHS}$ is probably more completely dissociated than is NaOII. The activity coefficient of $\mathrm{HS}^{-1}$ should, therefore, be unaffected by association just as it was unaffected by hydration.

If the effects of hydration and of association for hydroxide ion merely cancel, the approximation that $\gamma_{\mathrm{OH}^{-1}}=\gamma_{\mathrm{HS}^{-1}}$ should be valid. Going from $\mathrm{KCl}$ to $\mathrm{KOH}$, or from $\mathrm{RbCl}$ to $\mathrm{RbOH}$ gives a fairly good idea of the large effect of hydration of $\mathrm{OH}^{-1}$ on the mean ionic activity coefficient in the absence of appreciable association. In the transition from $\mathrm{NaCl}$ to $\mathrm{NaOH}$, however, there is practically no change of the mean ionic activity coefficient, which suggests that the hydration and association 
do indeed cancel each other. These considerations imply that in strong solutions $\gamma_{\mathrm{OH}^{-1}}$ in $\mathrm{KOH}$ solutions is not the same as $\gamma_{\mathrm{OH}^{-1}}$ in $\mathrm{NaOH}$ solutions. Thus although $\gamma_{\mathrm{OH}^{-1}}$ in $\mathrm{KOH}$ might be obtained directly by going from $\gamma_{ \pm \mathrm{KCl}}$ to $\gamma_{ \pm \mathrm{KOH}}$, the value of $\gamma_{\mathrm{OH}^{-1}}$ in $\mathrm{NaOH}$ would remain unknown. To get $\gamma_{\mathrm{OH}^{-1}}$ in $\mathrm{NaOH}$ each step of the substitutional chain must involve either no changes in hydration and association or compensating changes. This seems to be true for the sequence: $\gamma_{ \pm \mathrm{KCl}}=\gamma_{\mathrm{Cl}^{-1}}$, $\gamma_{ \pm \mathrm{NaCl}}, \gamma_{\mathrm{Na}^{+1}}, \gamma_{ \pm \mathrm{NaOH}}, \gamma_{\mathrm{OH}^{-1}}$. (Note, also, that going from $\gamma_{ \pm \mathrm{KCl}}$ to $\gamma_{ \pm \mathrm{KOH}}$ involves an uncompensated change due to hydration.) $\gamma_{\mathrm{OH}^{-1}}$ is then set equal to $\gamma_{\mathrm{HS}^{-1}}$. These values, derived from data quoted by LATIMER (1952), were used in subsequent work for ionic strengths greater than $0 \cdot 15$.

(b) Use of similarity of $\mathrm{HS}^{-1}$ and $\mathrm{Cl}^{-1}$. Another approach is to assume that the activity coefficient of $\mathrm{HS}^{-1}$ is the same as that for some other anion which has the same charge, and nearly the same size, hydration, etc. This seems to be the case for chloride ion. Writing $\gamma_{\mathrm{HS}^{-1}}=\gamma_{\mathrm{Cl}^{-1}}=\gamma_{ \pm \mathrm{KCl}}$ gives activity coefficients slightly lower than the first approach.

(c) Use of modification of Debye-Hückel theory. Finally the nature of various theoretical attempts to calculate activity coefficients in strong solutions was considered. According to MAcInnes (1939) the mean distance of closest approach, $a_{0}$, is "equal to the sum of the radii of oppositely charged ions in contact." This means that to calculate the activity coefficient of hydroxide ion $a_{0}$ is not taken equal to the diameter of hydroxide, but the cation present (e.g. sodium ion) must first be known and then the average diameter of this cation and of hydroxide must be computed. Since the same must be done to get the activity coefficient of the cation, it follows that the appropriate $a_{0}$ is the same for both cation and the anion in this particular solution. If hydroxide and a different cation (e.g. potassium ion) are considered then the average diameter of this new eation and hydroxide must be used. For any specific symmetrical electrolyte (but not necessarily for mixtures) this means that by considering only the Debye-Hückel expression,

$$
\log f_{N}=-A z^{2} \sqrt{\mu} /\left(1+B a_{0} \sqrt{\mu}\right)
$$

the computed activity coefficient for the cation equals that of the anion. A change in the dielectric constant ehanges $A$ and $B$, and may lead to additional terms in $\mu$. Again, however, the dielectric constant affects both cation and anion activity coefficients exactly the same. Similarly ion-pair formation, association, localized hydrolysis cte., affect both cation and anion in the same way since each ion-pair, or associated molecule, in effect removes (for a symmetrical electrolyte) the same number of cations as it does anions from the solution. The hydration of ions according to the theory of RoBINson and Stokes (1949) has two principal effects on the activity coefficient. The first is to decrease the activity of water, or conversely, to increase the apparent strength of the solute by removing water from the solvent and binding it to the solute. This increase of strength is obviously the same for the cation and the anion. The second effect is to increase the apparont diamoter of the ions. Normally the eation scems to be more highly hydrated, but since only the average diameter of cation and anion is used, the effect is, nevertheless, the same for both. Thus, the interesting result emerges that the Debye-Hückel theory and all of the modifications just mentioned treat the anion 
and cation of symmetrical electrolytes the same. It seems reasonable that any other effects not considered here will do likewise. It is then permissible to write $\gamma_{\mathrm{HS}^{-1}}=$ $\gamma_{ \pm \mathrm{NaHS}}$. Assuming as above that $\mathrm{HS}^{-1}$ is similar to $\mathrm{Cl}^{-1}, \gamma_{ \pm \mathrm{NaHS}}$ may be set equal to $\gamma_{ \pm \mathrm{NaCl}}$. This approximation gives a curve slightly higher than the first method.

\section{Activity coefficients in mixtures of $\mathrm{NaOH}$ and NaHS}

The association constant of $\mathrm{NaOH}$ is about 5 (GimbletT and Monk, 1954). Thus there is very little association of $\mathrm{Na}^{+1}$ and $\mathrm{OH}^{-1}$ at $\mathrm{pH}$ values less than $13 \cdot 0$ even in solutions $1 M$ in sodium ion. Since only a small percentage of the water is bound to $\mathrm{OH}^{-1}$ at this or lower $\mathrm{pH}$ values, the decrease of activity of water is slight. The hydration does increase the effective diameter of the $\mathrm{OH}^{-1}$.

Whatever the decrease in activity of water, the increase in strength of both $\mathrm{HS}^{-1}$ and $\mathrm{OH}^{-1}$ are in the same proportion. After the $\mathrm{OH}^{-1}$ is hydrated the size and charge of $\mathrm{OH}^{-1}$ are the same as for $\mathrm{HS}^{-1}$. Because little of the $\mathrm{OH}^{-1}$ is associated with $\mathrm{Na}^{+1}$ under the experimental conditions there is no decrease in concentration of $\mathrm{OH}^{-1}$ due to ion-pair formation, localized hydrolysis, etc.; this also appears to be the case for $\mathrm{HS}^{-1}$. Any changes in dielectric constant should affect both of these ions in the same way. Thus the Debye-Hückel equation or modifications of this equation ought to give the same activity coefficients for $\mathrm{HS}^{-1}$ and $\mathrm{OH}^{-1}$ for the solutions studied. Accordingly the curve for $\gamma_{\mathrm{OH}^{-1}}$ was taken the same as that for $\gamma_{\mathrm{HS}^{-1}}$. At ionic strengths less than 0.15 the Debye-Hückel equation, using $a_{0}=3.5 \AA$ as recommended by KIELLAXD (1937) was adopted with the approximation that $\gamma_{\mathrm{HS}^{-1}}=$ $f_{\mathrm{HS}^{-1}}$. At higher ionic strengths the first approximation mentioned above was used. This eurve is shown in Fig. 6.

\section{Activity coefficient of sulfide ion}

The derivation of the activity coefficient for sulfide ion is less satisfactory. KiELland (1937) recommends the use of $a_{0}$ equal to $5 \cdot 0$ in the Debye-Hückel equation. However, as mentioned above, adoption of the value of $\mathrm{p} K_{2}=12.89$ recommended by KURY, Zielen, and Latrmer (1953) and the use of their $\mathrm{pH}$ values in conjunction with the $\gamma_{\mathrm{HS}^{-1}}$ curve of Fig. 6 produces the lower $\gamma_{\mathrm{S}^{-2}}$ curve of Fig. 6. This curve corresponds to the Debye-Hückel equation with $a_{0}=0$ at ionic strengths less than $0 \cdot 15$. If the $\mathrm{pH}$ values obtained in this work, and $\mathrm{p} K_{2}-12.89$ were utilized, a different $\gamma_{\mathrm{S}^{-2}}$ curve lying above the $\gamma_{\mathrm{HS}^{-1}}$ values would result (not shown). It is thus apparent that the calculated activity coefficients for sulfide ion are extremely sensitive to a small error of $\mathrm{pH}$. Conversely, if the values of the activity coefficients are assumed, the calculated values of $\mathrm{p} K_{2}$ are very sensitive to $\mathrm{pH}$ errors. For this work the stoichiometric activity coefficient has been estimated as equal to the rational activity coefficient and the latter calculated from the Debye-Hückel equation using $a_{0}=5 \cdot 0$ (upper $\gamma_{\mathrm{s}^{-2}}$ curve in Fig. 6.) This curve can also be obtained by taking $a_{0}$ somewhat smaller, then increasing $f_{\mathrm{S}^{-2}}$ in accordance with the hydration effect and lowering it by converting to $\gamma_{s^{-2}}$. This curve and $\mathrm{p} K_{2}=13.50$ give good agreement with the measured $\mathrm{pH}$ 's.

\section{Errors arising from incorrect choices of activity coefficients}

Fortunately the sum of $\left[\mathrm{HS}^{-1}\right]$ and $\left[\mathrm{S}^{-2}\right]$ is not particularly sensitive to small errors in $\mathrm{pH}$ as long as consistent values for the $\gamma$ 's and $\mathrm{p} K_{2}$ are employed. Thus this 
sum calculated using $\mathrm{p} K_{2}=12 \cdot 89$ and the $\gamma$ 's derived from KoNOPIK and LEBERL's (1949) data is almost exactly the same as the sum obtained using $\mathrm{p} K_{2}=13.50$ and the $\gamma$ 's assumed in this paper. In a similar manner the calculated amount of $\mathrm{HS}^{-1}$ will always be the same as the calculated amount of $\mathrm{OH}^{-1}$. If the $\mathrm{pH}$ measurements are consistently high, this will lead to a $\mathrm{p} K_{2}$ that is too high and a $\mathrm{pOH}$ that is too low, if the assumed activity coefficient curves are not simultaneously changed. This leads to a change in the free energy of formation of sulfide ion, and this in turn to a change in the standard potential of the $\mathrm{Ag} / \mathrm{Ag}_{2} \mathrm{~S}$ electrode. If this electrode is used to estimate sulfide ion activity, the $\mathrm{pS}$ obtained will then be too high. By inserting the activities of hydrogen and sulfide ions into the expression for the second dissociation constant for $\mathrm{H}_{2} \mathrm{~S}$, with the new $\mathrm{p} K_{2}$, a value of $\mathrm{pHS}$ is obtained which is too low. Calculation shows that this lowering of pHS is almost exactly the lowering of $\mathrm{pOH}$. A similar result is obtained if the $\gamma$ 's are changed and $\mathrm{p} K_{2}$ kept constant. In all subsequent work only the sum of [IIS-] and $\left[\mathrm{S}^{-2}\right]$, or the relative magnitude of $\left[\mathrm{HS}^{-1}\right]$ and $\left[\mathrm{OH}^{-1}\right]$ is of critical importance. As long as the activity coefficients are consistent with the accepted $\mathrm{p} K_{2}$ the sum of $\left[\mathrm{HS}^{-1}\right]$ and $\left[\mathrm{S}^{-2}\right]$ will be correct, and $\left[\mathrm{HS}^{-1}\right]$ will equal $\left[\mathrm{OH}^{-1}\right]$.

Because the use of the upper $\gamma_{\mathrm{S}^{-2}}$ curve in Fig. 6 and $\mathrm{p} K_{2}=13.50$ gave consistent and reproducible results in agreement with experiments these values were adopted. This implies that any errors of $\mathrm{pH}$ due to oxidation, loss of $\mathrm{H}_{2} \mathrm{~S}$ etc., are consistent and are in some manner incorporated into the $\mathrm{p} K_{2}$ and $\gamma_{\mathrm{S}^{-2}}$ values chosen. This value of $\mathrm{p} K_{2}$ lies between those of Maronny (1959a) and of KURY, Zimene, and LATIMER (1953).

All other constants, such as $E^{\circ}$ for the $\mathrm{Ag} / \mathrm{Ag}_{2} \mathrm{~S}$ electrode, were calculated to agree with these choices.

\section{Activity coefficients for polysulfides}

Activity coefficients for polysulfide ions were calculated from the Debye-Hückel equation by choosing the $a_{0}$ 's approximately equal to chain length. For $\mathrm{S}_{4}{ }^{-2}, \mathrm{~S}_{5}{ }^{-2}$, and $S_{6}{ }^{-2}, a_{0}$ 's were taken as 10,12 , and $14 \AA$, respectively. These were estimated by taking the radii of the two sulfur atoms on the ends of the chain equal to that of $\mathrm{S}^{-2}$, and the radii of intermediate sulfur atoms equal to that of elemental $\mathrm{S}$. This corresponds to FEHÉR and BERTHOLD's (1954) observation that the molar volume of polysulfide ions can be estimated in a similar way. The length was found by assuming a zigzag chain with tetrahedral bond angles. MARonvy (1959b) used similar values for $a_{0}$. Any effects that might arise due to the separation of charge in the longer polysulfide chains have been assumed negligible.

\section{Calculations Based on Experimental Results}

By proceeding to the interpretation of the experimental data a model for the distribution of various sulfide and polysulfide species in the solutions studied can be derived. The data for experiments where no $\mathrm{H}_{2} \mathrm{~S}$ was added will be considered first.

\section{Absence of hydropolysulfide ions}

From the measured $\mathrm{pH}$, corrected to $25^{\circ} \mathrm{C}$, and the value of $\mathrm{p} K_{w}$, the $\mathrm{pOH}$ can be calculated directly. The measurements of potentials with the $\mathrm{Ag} / \mathrm{Ag}_{2} \mathrm{~S}$ electrode, 
with the $E^{\circ}$ corrected to the temperature of measurement using entropy data from KURY, ZIELEN, and LATIMER (1953), are then employed to calculate pS. Since $d\left(\mathrm{p} K_{2}\right) / d t \simeq d\left(\mathrm{p} K_{W}\right) / d t, d(\mathrm{pS}) / d t \simeq 0$. By combining this $\mathrm{pS}$, the measured $\mathrm{pH}$, and the value of $\mathrm{p} K_{2}$ at $25^{\circ} \mathrm{C}$, the pHS is obtained. As is shown in Figs. 7 and $8 \mathrm{pHS}$

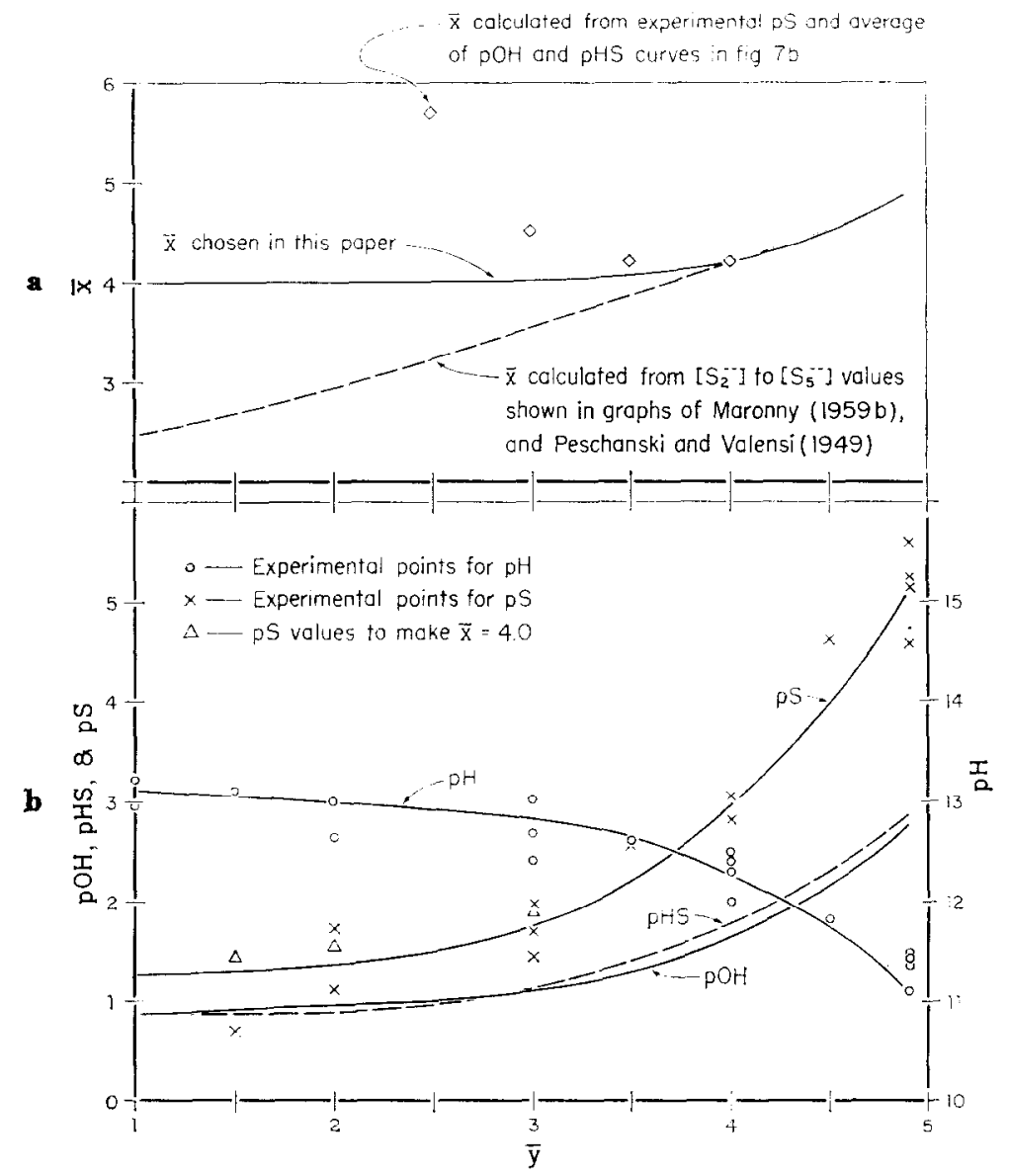

Fig. 7. (a) Plot of $\bar{x}$ vs. $\bar{y}$ for solutions $1.0 \mathrm{M}$ in Na $\mathrm{Na}^{+1}$ (b) Plot of experimentally determined $\mathrm{pH}$ and $\mathrm{pS}$ values (corrected to $25^{\circ} \mathrm{C}$ ) vs. $\bar{y}$ in solutions $1.0 \mathrm{M}$ in $\mathrm{Na}^{+1}$. Curves for $\mathrm{pH}$ and $\mathrm{pS}$ are drawn to give the best fit with the experimental data. $\mathrm{pOH}$ is calculated from $\mathrm{pH}$, and $\mathrm{pHS}$ is calculated from $\mathrm{pH}$ and $\mathrm{pS}$.

equals pOH within the experimental error, but in Fig. 9 the agreement is quite poor. Ignoring this last plot, the data at molarities of sodium ion of 1.0 and $0.6 \mathrm{imply}$ that no hydropolysulfides or hydrogen polysulfides are present. If they were, there should be additional hydroxide produced by the reactions:

$$
\begin{aligned}
\mathrm{S}_{x}^{-2}+\mathrm{H}_{2} \mathrm{O} & =\mathrm{HS}_{x}^{-1}+\mathrm{OH}^{-1}, \\
\mathrm{HS}_{x}^{-1}+\mathrm{H}_{2} \mathrm{O} & =\mathrm{H}_{2} \mathrm{~S}_{x}+\mathrm{OH}^{-1}
\end{aligned}
$$

This result thus confirms the assumption of Peschanski and Valensi (1949) and of Maronny (1959b) that hydropolysulfides are absent. 


\section{Calculation of $\bar{x}$}

The procedure for calculating $\bar{x}$ is to subtract the amount of $\mathrm{HS}^{-1}$ and $\mathrm{S}^{-2}$ from the total $\mathrm{S}$ and monosulfide, respectively, and to compute the ratio of these two quantities. Since hydropolysulfide ions and hydrogen polysulfides are absent, the expression for $\bar{y}$ becomes

$$
\bar{y}=\left\{\left[\mathrm{HS}^{-1}\right]+\left[\mathrm{S}^{-2}\right]+\sum_{x=2}^{\infty} x\left[\mathrm{~S}_{x}^{-2}\right]\right\} /\left\{\left[\mathrm{HS}^{-1}\right]+\left[\mathrm{S}^{-2}\right]+\sum_{x=2}^{\infty}\left[\mathrm{S}_{x}^{-2}\right]\right\}
$$

From the calculations just made, we know the activity of both $\mathrm{HS}^{-1}$ and $\mathrm{S}^{-2}$.

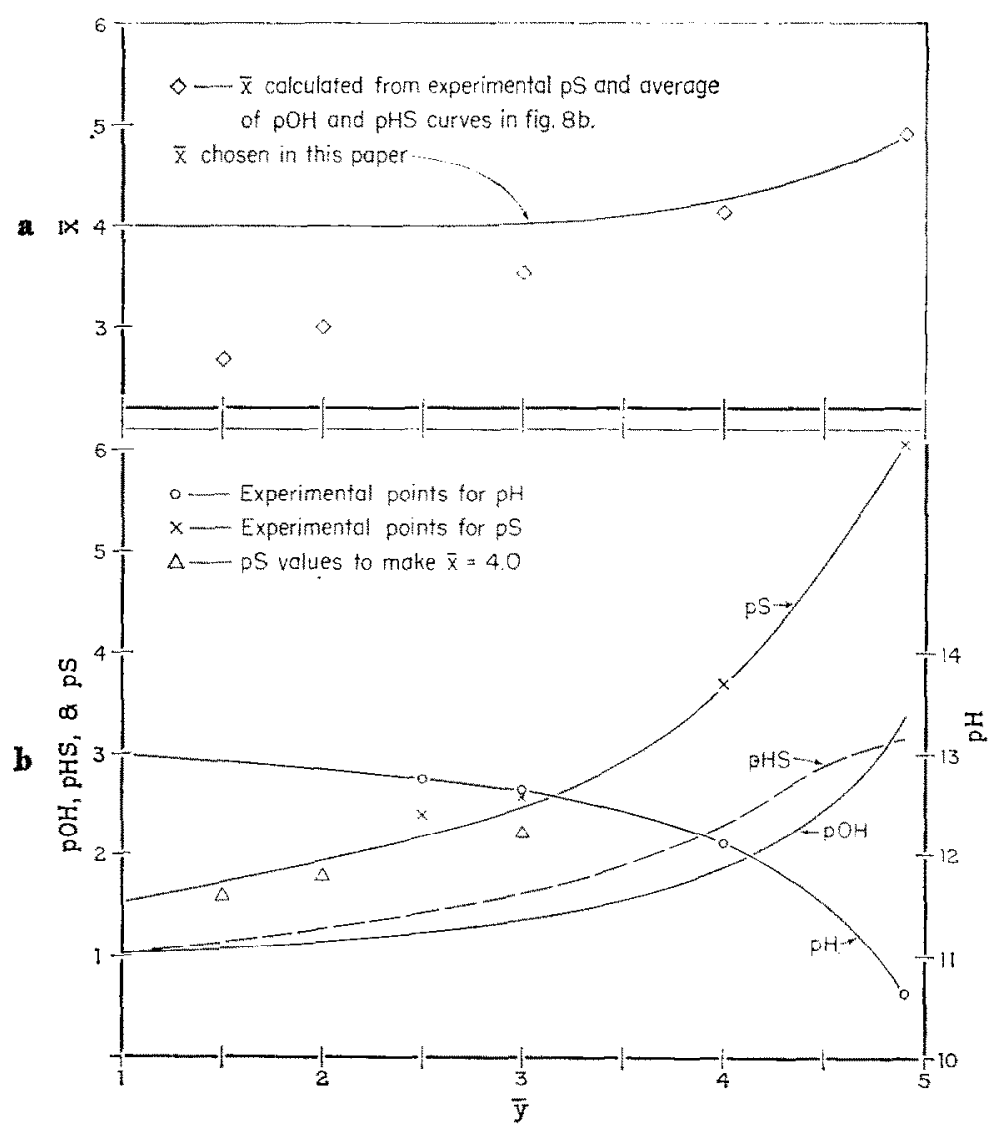

Fig. 8. (a) Plot of $\bar{x}$ vs. $\bar{y}$ for solutions $0 \cdot 6 \mathrm{M}$ in $\mathrm{Na}^{+1}$. (b) Plot of experimentally determined $\mathrm{pH}$ and $\mathrm{pS}$ values (corrected to $25^{\circ} \mathrm{C}$ ) vs. $\bar{y}$ in solutions $0.6 \mathrm{M}$ in $\mathrm{Na}^{+1}$. Curves for $\mathrm{pH}$ and $\mathrm{pS}$ are drawn to give the best fit with the experimental data. $\mathrm{pOH}$ is calculated from $\mathrm{pH}$, and $\mathrm{pHS}$ is calculated from $\mathrm{pH}$ and $\mathrm{pS}$.

From estimations of the ionic strength the activity coefficients are approximated and in turn first estimates of the concentrations of $\mathrm{HS}^{-1}$ and $\mathrm{S}^{-2}$. It also follows from the previous calculations that $\left[\mathrm{OH}^{-1}\right]=\left[\mathrm{HS}^{-1}\right]$. By subtracting the sum of $\left[\mathrm{HS}^{-1}\right]$ and $\left[\mathrm{S}^{-2}\right]$ from the original concentration of $\mathrm{Na}_{2} \mathrm{~S}$ the concentration of polysulfide ion is obtained. This gives first estimates of the sum of the concentrations of divalent ions 
and separately of the sum of the concentrations of univalent ions. This makes possible an improved estimate of ionic strength, and the cycle can be repeated until constant values are obtained.

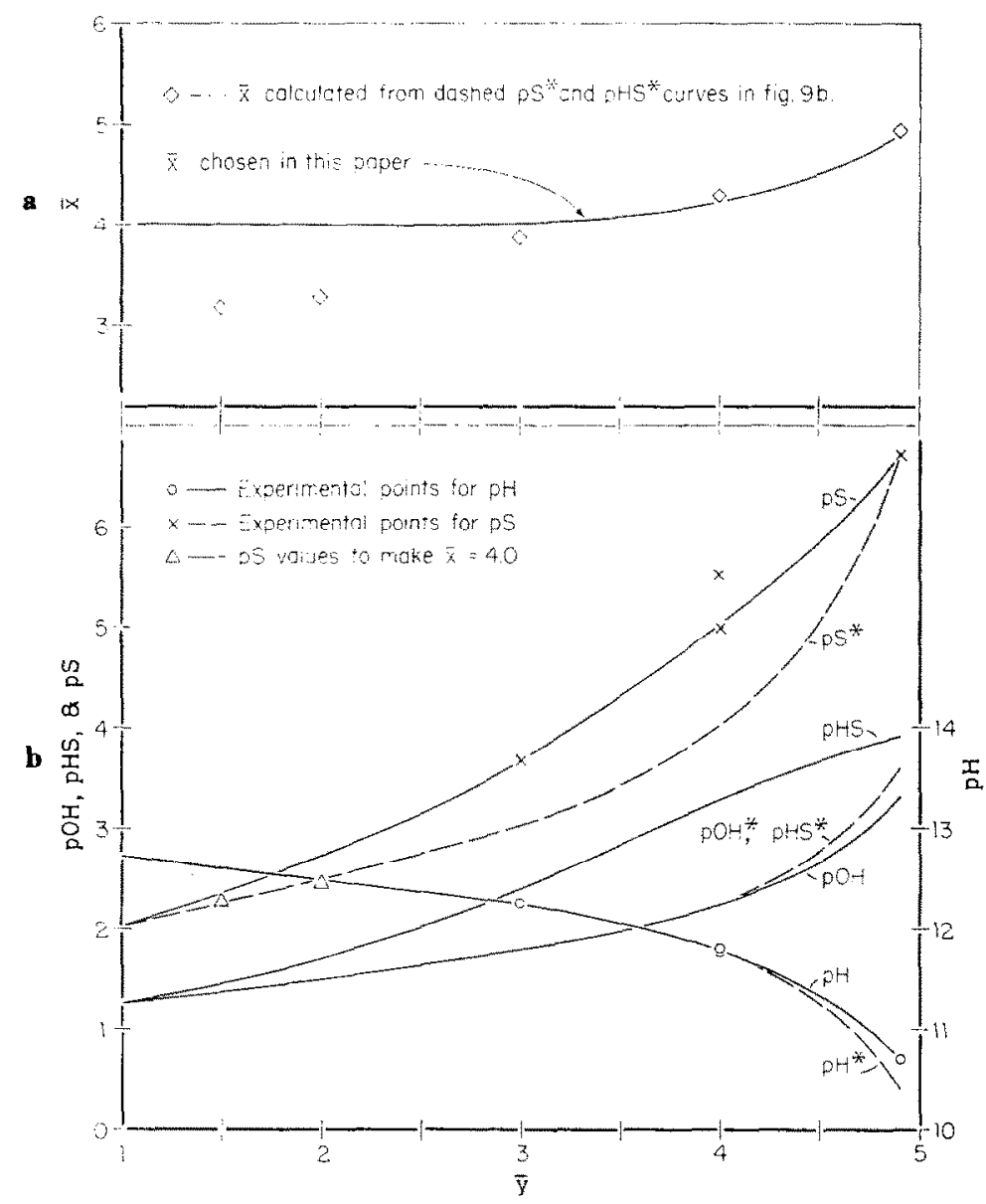

Fig. 9. (a). Plot of $\vec{x}$ vs. $\vec{y}$ for solutions $0.2 \mathrm{M}$ in $\mathrm{Na}^{+1}$. (b) Plot of $\mathrm{pH}, \mathrm{ps}, \mathrm{pOH}$, and $\mathrm{pHS}$ (corrected to $25^{\circ} \mathrm{C}$ ) vs. $\bar{y}$ for solutions $0.2 \mathrm{M}$ in $\mathrm{Na}^{+1}$. Solid curves for $\mathrm{pH}$ and $\mathrm{pS}$ are drawn to give the best fit to experimental data, and for $\mathrm{pHS}$ and $\mathrm{pOH}$ are calculated from $\mathrm{pH}$ and $\mathrm{pS}$. The dashed $\mathrm{pH}^{*}$ and $\mathrm{pOH}^{*}$ lines are adjusted so as to give the measured $\mathrm{pS}$ at $\bar{y}=4 \cdot 9$, assuming $\mathrm{pHS}=\mathrm{pOH}$. The dashed $\mathrm{pOH}^{*}$ line is adjusted to agree with $\mathrm{pOH}^{*}$. $\mathrm{pS}^{*}$ is calculated from the adjusted $\mathrm{pH}^{*}$ and pHS* lines.

Subtracting the sum of $\left[\mathrm{HS}^{-1}\right]$ and $\left[\mathrm{S}^{-2}\right]$ from both numerator and denominator of the right hand member of equation (2) yields

$$
\bar{x}=\sum_{x=2}^{\infty} x\left[\mathrm{~S}_{x}^{-2}\right] / \sum_{x=2}^{\infty}\left[\mathrm{S}_{x}{ }^{-2}\right]
$$

This value of $\bar{x}$ is plotted in Fig. 7 for solutions $1 \mathrm{M}$ in sodium ion $(0.5 \mathrm{M}$ in monosulfide). It is assumed that the $\mathrm{pH}$ data are more reliable than the $\mathrm{pS}$ measurements. By correcting the $\mathrm{pS}$ values on the hypothesis that $\mathrm{pOH}=\mathrm{pHS}$ the interesting 
relation appears that $\bar{x}$ never decreases below 4 even for solutions with very low $\bar{y}$. Actually some of the originally calculated values at low $\bar{y}$ were much higher (up to 30 ), but by adjusting the experimental values of $\mathrm{pH}$ and $\mathrm{pS}$ to a small extent, as shown by triangles in Figs. 7, 8, and 9, the calculated $\bar{x}$ could be decreased sharply. This was done because it seemed quite unreasonable that $\bar{x}$ should increase as $\bar{y}$ decreased. The value of 4 was chosen as a reasonable value because it gave the best fit with the $\mathrm{pH}$ and $\mathrm{pS}$ values measured here. Maronny's (1959b) $\mathrm{pH}$ data imply that $\bar{x}$ is higher than 4 at low $\bar{y}$, but his final graph of the distribution implies an $\bar{x}<4$.

The values of $\bar{x}$ obtained differ markedly at low $\bar{y}$ from those derived from the graphical representations given by Peschanski and VaLensi (1949) or by Maronny (1959b) (cf. Fig. 7). If their total of $\left[\mathrm{HS}^{-1}\right]$ and $\left[\mathrm{S}^{-2}\right]$ is recalculated using $\mathrm{p} K_{2}=$ 13.50 in order to achieve consistency of $\mathrm{pH}, \mathrm{pS}$, and $\mathrm{pHS}$ values, it is found that a $\mathrm{pH}$ decrease of 0.1 and a $\mathrm{pS}$ increase of about 0.2 will convert the data given in the present paper so as to give their $\bar{x}$ curve. Thus $\bar{x}$ is extremely sensitive to small errors in $\mathrm{pH}$ and $\mathrm{pS}$.

Comparison with work of Valensi and co-workers

The original experimental $\mathrm{pH}$ data of Peschanski and Valensi (1949) is internally inconsistent and differs markedly from that reported by MARONNY $(1959 \mathrm{a}, \mathrm{b})$ and by Maronny and Valensi $(1955,1958,1959)$. The data in the latter four papers agree closely with the present work. By using the latter $\mathrm{pH}$ data and $\mathrm{p} K_{W}, \mathrm{pOH}$ is easily found. By assuming that $\mathrm{pOH}=\mathrm{pHS}$ and by using $\mathrm{p} K_{2}, \mathrm{pS}$ is computed. Thus a change in $\mathrm{pH}$ is a measure of the change in the amounts of hydrosulfide and sulfide ions. The less the $\mathrm{pH}$ decreases, the less is the decrease in the concentrations of $\mathrm{HS}^{-1}$ and $\mathrm{S}^{-2}$. It is seen from equation (2) with $\vec{y}=2$, that

and by using equation (3) that

$$
\left[\mathrm{HS}^{-1}\right]+\left[\mathrm{S}^{-2}\right]=\sum_{x=2}^{\infty} x\left[\mathrm{~S}_{x}^{-2}\right]-2 \sum_{x=2}^{\infty}\left[\mathrm{S}_{x}^{-2}\right],
$$

$$
\left[\mathrm{HS}^{-1}\right]+\left[\mathrm{S}^{-2}\right]=(\bar{x}-2) \sum_{x=2}^{\infty}\left[\mathrm{S}_{x}^{-2}\right]
$$

There is also the relation

$$
c=\left[\mathrm{HS}^{-1}\right]+\left[\mathrm{S}^{-2}\right]+\sum_{x=2}^{\infty}\left[\mathrm{S}_{x}^{-2}\right]
$$

Using this to eliminate $\sum_{x=2}^{\infty}\left[\mathrm{S}_{x}{ }^{-2}\right]$ the expression becomes

$$
\left[\mathrm{HS}^{-1}\right]+\left[\mathrm{S}^{-2}\right]=(\tilde{x}-2)\left(c-\left[\mathrm{HS}^{-1}\right]-\left[\mathrm{S}^{-2}\right]\right)^{*}
$$

The less the $\mathrm{pH}$ changes between $\bar{y}=1$ and $\bar{y}=2$ at fixed $c$, the smaller is the quantity $\left(c-\left[\mathrm{HS}^{-1}\right]-\left[\mathrm{S}^{-2}\right]\right)$ and since $\left[\mathrm{HS}^{-1}\right]+\left[\mathrm{S}^{-2}\right]$ has changed only a little, the larger is $\bar{x}$. Maronny's data show less change of $\mathrm{pH}$ from $\bar{y}=1$ to $\bar{y}=2$ than the data reported here. Therefore, $\bar{x}$ calculated from his data should be greater than 4 at $\bar{y}=2$, not less as is implied by his final model which is reproduced here as Fig. 12. Partly because of this the value of $\bar{x}$ is taken as varying only between 4 and 5 in spite of its extreme sensitivity to small errors in $\mathrm{pH}$.

* More generally this equation is:

$$
(\bar{y}-1)\left(\left[\mathrm{HS}^{-1}\right]+\left[\mathrm{S}^{-2}\right]\right)=(\bar{x}-\bar{y})\left(c-\left[\mathrm{HS}^{-1}\right]-\left[\mathrm{S}^{-2}\right]\right)
$$


Implications of $\bar{x} \geqq 4$

In order to get an average value of $x=4$ various distributions can be postulated. There might be equal amounts of $\mathrm{S}_{2}{ }^{-2}$ and $\mathrm{S}_{6}{ }^{-2}$ with no intermediate polysulfides, or $\mathrm{S}_{4}^{-2}$ only, etc.

There are no gaps in the homologous series of hydrogen polysulfides (cf. Fenḱr et al., 1956; FehÉr and Wrnkraus, 1956). Because the polysulfide ions are chains it seems unlikely that the energy required to add or subtract a sulfur atom is very great. It therefore seems unlikely that gaps exist in the sequence of polysulfide ions. As a reasonable limiting case it may be assumed that $\mathrm{S}_{2}^{-2}, \mathrm{~S}_{3}^{-2}, \mathrm{~S}_{4}^{-2}, \mathrm{~S}_{5}^{-2}$, and $\mathrm{S}_{6}{ }^{-2}$ are all equal in amount (i.e. it seems unlikely that $\mathrm{S}_{6}{ }^{-2}$ or $\mathrm{S}_{5}{ }^{-2}$ are greater than $\mathrm{S}_{4}{ }^{-2}$ at low $\bar{y}$ where $\bar{x}=4$ ). In this case the amount of $\mathrm{S}_{2}{ }^{-2}$ at low $\bar{y}$ is only $1 / 5$ of the total amount of polysulfide ions. Since this total is small, as calculated by subtracting the sum of $\left[\mathrm{HS}^{-1}\right]$ and $\left[\mathrm{S}^{-2}\right]$ from initial sulfide, the amount of $\mathrm{S}_{2}^{-2}$ is at most small. The same applies to the amount of $\mathrm{S}_{3}{ }^{-2}$ but not so strongly.

These relations suggest that both disulfide and trisulfide ions may be negligible in amount at low $\bar{y}$. At higher $\bar{y}$ they are expected to be less abundant because of reaction to form polysulfides containing more S. Since $\bar{x}$ varies only between 4 and 5 the further hypothesis is now adopted that only $\mathrm{S}_{4}^{-2}$ and $\mathrm{S}_{5}{ }^{-2}$ are of importance, and this assumption is tested against the experimental data. With these postulates it is now possible to calculate the amounts of all the ions assumed to be in the solution. The amounts of $S_{4}^{-2}$ and $S_{5}^{-2}$ are found from the two equations,

$$
\begin{gathered}
\bar{x}=\left\{4\left[\mathrm{~S}_{4}^{-2}\right]+5\left[\mathrm{~S}_{5}^{-2}\right]\right\} /\left\{\left[\mathrm{S}_{4}^{-2}\right]+\left[\mathrm{S}_{5}{ }^{-2}\right]\right\}, \\
c-\left[\mathrm{HS}^{-1}\right]-\left[\mathrm{S}^{-2}\right]=\left[\mathrm{S}_{4}^{-2}\right]+\left[\mathrm{S}_{5}^{-2}\right]
\end{gathered}
$$

All other concentrations are calculated as described above. The results are compiled in Table 4 for solutions $1 \mathbf{M}$ in sodium ion.

\begin{tabular}{|c|c|c|c|c|c|c|c|c|c|c|c|c|c|c|}
\hline$y$ & $\gamma \mathrm{Hs}^{-1}$ & $\gamma_{s-2}$ & $\mathrm{pHS}$ & $\mathrm{pS}$ & {$\left[\mathrm{HS}^{-}\right]$} & {$\left[\mathrm{S}^{-2}\right]$} & $\begin{array}{c}\bar{x} \\
\text { cale. }\end{array}$ & $\left\{\begin{array}{l}c \\
{\left[\mathbf{H S}^{-1}\right]} \\
-\left[\mathrm{S}^{-2}\right]\end{array}\right.$ & $\begin{array}{c}\bar{x} \\
\text { ass- } \\
\text { umed }\end{array}$ & {$\left[\mathrm{S}_{4}^{-2}\right]$} & {$\left[\mathrm{S}_{5}-\mathbf{2}\right]$} & Eh & $E_{4}{ }^{\circ}$ & $E_{5}$ \\
\hline $1 \cdot 0$ & $0 \cdot 640$ & $0 \cdot 155$ & 0.93 & $1 \cdot 31$ & $0 \cdot 184$ & 0.316 & — & 0 & $\ldots$ & 0 & 0 & - & - & - \\
\hline 1.5 & 0.638 & $0 \cdot 153$ & 0.965 & $1 \cdot 43$ & $0 \cdot 170$ & 0.243 & $3 \cdot 88$ & $0 \cdot 087$ & $4 \cdot 00$ & 0.087 & 0 & -0.485 & -0.525 & \\
\hline $2 \cdot 0$ & 0.637 & 0.152 & 1.02 & 1.55 & $0 \cdot 150$ & 0.185 & 4.04 & 0.165 & 4.00 & 0.165 & 0 & -0.466 & -0.514 & . \\
\hline $3 \cdot 0$ & 0.030 & 0.149 & $1 \cdot 20$ & 1.90 & 0.099 & 0.084 & $4 \cdot 15$ & 0.317 & 4.03 & 0.307 & 0.010 & -0.438 & -0.503 & -0.490 \\
\hline $4 \cdot 0$ & 0.635 & $0 \cdot 147$ & $1 \cdot 70$ & 3.00 & 0.031 & 0.007 & $4 \cdot 25$ & 0.462 & $4 \cdot 25$ & $0 \cdot 346$ & $0 \cdot 116$ & -0.402 & -0.510 & -0.503 \\
\hline 4.5 & $0 \cdot 634$ & $0 \cdot 146$ & $2 \cdot 28$ & $4 \cdot 10$ & 0.008 & 0.001 & $4 \cdot 57$ & 0.491 & $4 \cdot 57$ & 0.211 & 0.280 & -0.354 & -0.503 & -0.498 \\
\hline $4 \cdot 9$ & $0 \cdot 634$ & $0 \cdot 145$ & $3 \cdot 00$ & $5 \cdot 50$ & 0.002 & 一 & $4 \cdot 91$ & $0 \cdot 498$ & $4 \cdot 91$ & 0.044 & 0.454 & -0.314 & -0.511 & -0.511 \\
\hline & & & & & & & & & & & & & -0.5 & $-0.500_{5}$ \\
\hline
\end{tabular}

Table 4

These values of $\left[\mathrm{S}_{4}{ }^{-2}\right]$ and $\left[\mathrm{S}_{5}{ }^{-2}\right]$ and the experimental Eh uncorrected for temperature variation (cf. Fig. 4) are used to calculate approximate standard potentials for the two reactions,

$$
\begin{aligned}
& 4 \mathrm{~S}^{-2}=\mathrm{S}_{4}^{-2}+6 e^{-1} \\
& 5 \mathrm{~S}^{-2}=\mathrm{S}_{5}^{-2}+8 e^{-1}
\end{aligned}
$$


The standard potentials thus calculated from the equations,

and

$$
\mathrm{Eh}=E_{4}{ }^{\circ}+(0 \cdot 059 / 6) \log \left[\left(\mathrm{S}_{4}{ }^{-2}\right) /\left(\mathrm{S}^{-2}\right)^{4}\right]
$$

$$
\mathrm{Eh}=E_{5}{ }^{\circ}+(0 \cdot 059 / 8) \log \left[\left(\mathrm{S}_{5}^{-2}\right) /\left(\mathrm{S}^{-2}\right)^{5}\right]
$$

are also compiled in Table 4 . The nearly constant values over practically the entire range of $\bar{y}$ lends considerable support to the simple model assumed. The average value of $E_{4}^{\circ}$ is $-0.508 \mathrm{~V}$ and of $E_{5}{ }^{\circ}$ is $-0.500_{5} \mathrm{~V}$.

\section{Calculated maximum $\bar{y}$}

(a) With no $\mathrm{H}_{2} \mathrm{~S}$ added. From these average values it is a simple matter to obtain an approximate standard free energy of the reactions, and in turn to use the free energy of formation of $\mathrm{S}^{-2}$ and get that of $\mathrm{S}_{4}^{-2}$ and of $\mathrm{S}_{5}^{-2}$.

A further test of the hypothesis can be made by noticing that at saturation in sulfur both $\mathrm{HS}^{-1}$ and $\mathrm{S}^{-2}$ are negligible. Moreover, the reaction,

$$
\mathrm{S}_{4}^{-2}+\mathrm{S}=\mathrm{S}_{5}^{-2}
$$

is involved since solid $S$ is present. From the free energies just obtained the equilibrium constant for this reaction is found to be 2.88. This is the ratio of $S_{5}{ }^{-2}$ to $S_{4}{ }^{-2}$ and since these are the only sulfur species presumed to be present implies a $\bar{y}$ of $\mathbf{4} \cdot \mathbf{7 2}$. This is less than the observed maximum, and implies that the model is not yet complete. The same objection can be applied to the work of Peschanskr and Valensi (1949), of Maronny (1959b), and of Maronny and Valensi (1955, 1958, 1959). To correct this discrepancy it was necessary to assume that there is also some hexasulfide, $\mathrm{S}_{6}{ }^{-2}$, in the solution. Thus one of the basic assumptions of the work by VALENSI and co-workers was not confirmed.

The necessity for including $\mathrm{S}_{6}{ }^{-2}$ can also be shown in another way. The reaction $\mathrm{S}^{-2}+3 \mathrm{~S}_{5}^{-2}=4 \mathrm{~S}_{4}^{-2}$ is always involved in polysulfide solutions. By using the relations :

$$
\begin{gathered}
\Delta F^{\circ}=n \mathcal{F} E^{\circ}, \quad \Delta F^{\circ}=-R T \log _{e} K, \text { and } \\
\left(\mathrm{S}_{4}^{-2}\right)^{4} /\left(\mathrm{S}^{-2}\right)\left(\mathrm{S}_{5}^{-2}\right)^{3}=K,
\end{gathered}
$$

the equation

$$
24\left(E_{4}^{\circ}-E_{5}^{\circ}\right) / 0 \cdot 059=4 \mathrm{pS}_{4}^{-2}-3 \mathrm{pS}_{5}^{-2}-\mathrm{pS}^{-2}=\mathrm{p} K
$$

is derived. When the solution is saturated in $\mathrm{S}, \mathrm{pS}$ can be estimated with the $\mathrm{Ag} / \mathrm{Ag}_{2} \mathrm{~S}$ electrode. Because $\bar{y}$ is approximately $4 \cdot 9$ and only $\mathrm{S}_{4}{ }^{-2}$ and $\mathrm{S}_{5}{ }^{-2}$ are presumed to be present, it follows that:

$$
9\left[\mathrm{~S}_{4}^{-2}\right]=\left[\mathrm{S}_{5}^{-2}\right]
$$

Use of $\gamma_{\mathrm{S}_{4}-2}=0.320$ and $\gamma_{\mathrm{S}_{5}-2}=0.375$ for solutions $\mathrm{l} \mathrm{M}$ in $\mathrm{Na}^{+1}$ gives the values $\mathrm{pS}_{4}{ }^{-2}=1.796$ and $\mathrm{pS}_{5}{ }^{-2}=0.773$. Taking $\mathrm{pS}^{-2}=5.5$ from Table 4 gives $\mathrm{p} K=$ $-0 \cdot 635$, or

$$
E_{4}^{\circ}-E_{5}^{\circ}=-0.0016 \mathrm{~V}
$$

This calculated difference of the $E^{\circ}$ s is markedly smaller than the difference of 
$0.006 \mathrm{~V}$ determined here from the experimental data or the difference of $0.005 \mathrm{~V}$ derived from Maronny's (1959b) data. It is precisely this very small difference of two relatively large numbers that makes the problem of finding the correct distribution of polysulfide species so difficult.

It is assumed that at the least

$$
E_{5}^{\circ}-E_{4}{ }^{\circ}=0 \cdot 004 \mathrm{~V}
$$

The standard potential of the reaction,

$$
\mathrm{S}^{-2}=\mathrm{S}+2 e^{-1}
$$

can be obtained from the second dissociation constant of $\mathrm{H}_{2} \mathrm{~S}$ and the standard free energy of formation of $\mathrm{HS}^{-1}$ ion. This potential, $E_{\mathrm{I}}^{\circ}$, is $-0.46444 \mathrm{~V}$. (The last 2 places are not significant, but are useful for consistency in avoiding errors in the calculations due to rounding.)

(b) Saturated in $\mathrm{H}_{2} \mathrm{~S}$ assuming no $\mathrm{HS}_{x}^{-1}$. From the reaction, $\mathrm{S}_{4}^{-2}+\mathrm{S}=\mathrm{S}_{5}^{-2}$, the values of $E_{4}{ }^{\circ}, E_{5}{ }^{\circ}, E_{\Upsilon}{ }^{\circ}$, and Eqns. (4) and (5) it is now possible to derive the relation:

$$
4 E_{5}^{\circ}-3 E_{4}^{\circ}=-0.49462 \mathrm{~V}
$$

as follows. Multiplying Eqns. (4) and (5) by 6 and 8 respectively, and converting to neg. log. units gives:

$$
\begin{aligned}
& 6 \mathrm{Eh}=6 E_{4}^{\circ}-0.059 \mathrm{pS}_{4}^{-2}+4 \times 0.059 \mathrm{ps}^{-2} \\
& 8 \mathrm{Eh}=8 E_{5}^{\circ}-0.059 \mathrm{pS}_{5}^{-2}+5 \times 0.059 \mathrm{pS}^{-2}
\end{aligned}
$$

The Nernst equation corresponding to reaction (9) is multiplied by 2 to obtain:

$$
2 \mathrm{Eh}=2 \times-0.46444+0.059 \mathrm{pS}^{-2}
$$

Adding Eqn. (11) and (13) and subtracting Eqn. (12) gives

$$
0.059\left(\mathrm{pS}_{5}^{-2}-\mathrm{pS}_{4}^{-2}\right)=8 E_{5}^{0}-6 E_{4}{ }^{\circ}+2 \times 0.46444
$$

From Eqn. (6) and the activity coefficients of pentasulfide and tetrasulfide ions it is found that $\mathrm{pS}_{5}{ }^{-2}-\mathrm{pS}_{4}^{-2}$ equals -1.02312 when an $0.5 \mathrm{M}$ solution of $\mathrm{Na}_{2} \mathrm{~S}$ is saturated in S. Introducing this into Eqn. (14) and simplifying gives Eqn. (10).

Solving Eqn. (8) and (10) yields $E_{5}^{\circ}=-0.50662$ and $E_{4}^{\circ}=-0.51062$. These values lie below final estimates made here and those calculated from Maronny's (1959b) free energy values. For the reaction, $\mathrm{S}^{-2}+4 \mathrm{~S}=\mathrm{S}_{5}{ }^{-2}$, the relation,

$$
\mathrm{pS}_{5}{ }^{-2}-\mathrm{pS}=8\left(E_{5}^{\circ}-E_{1}^{\circ}\right) / 0 \cdot 059=-5 \cdot 72
$$

is valid as long as sulfide ion, pentasulfide ion, and solid $S$ are present at equilibrium. Therefore, it may be used for $\mathrm{Na}_{2} \mathrm{~S}$ solutions saturated in both $\mathrm{S}$ and $\mathrm{H}_{2} \mathrm{~S}$. Experimentally, for $1 \mathrm{M} \mathrm{Na}^{+1}$ the $\mathrm{pH}$ is found to be $7 \cdot 65$ and $\bar{y}=1 \cdot 29$. For a $\mathrm{pH}$ of $7 \cdot 65$ the relation, $\mathrm{pS}=\mathrm{pHS}+5 \cdot 85$, follows from the use of the second dissociation constant of $\mathrm{H}_{2} \mathrm{~S}$. Substituting this expression for $\mathrm{pS}$ into Eqn. (15) gives

$$
\mathrm{pS}_{5}-2-\mathrm{pHS}=0.13
$$


At this $\mathrm{pH}$, and with solutions saturated in $\mathrm{S}$, the only ions present in appreciable amount (ignoring for the moment $\mathrm{HS}_{5}{ }^{-1}, \mathrm{HS}_{4}^{-1}$, etc.) are $\mathrm{Na}^{+1}, \mathrm{HS}^{-1}, \mathrm{~S}_{4}^{-2}$, and $\mathrm{S}_{5}{ }^{-2}$. Since electrical neutrality must be maintained, the relation

$$
\left[\mathrm{Na}^{+1}\right]=1 \cdot 000=\left[\mathrm{HS}^{-1}\right]+2\left[\mathrm{~S}_{4}^{-2}\right]+2\left[\mathrm{~S}_{5}{ }^{-2}\right]
$$

must hold. Eqn. 16, after the activity coefficients have been estimated, gives the ratio of $\left(\mathrm{HS}^{-1}\right):\left(\mathrm{S}_{5}{ }^{-2}\right)$, and Eqn. (6) gives that of $\left(\mathrm{S}_{4}{ }^{-2}\right):\left(\mathrm{S}_{5}{ }^{-2}\right)$. Substituting these ratios into Eqn. (17), it is found that $\left[\mathrm{HS}^{-1}\right]=0 \cdot 266,\left[\mathrm{~S}_{4}{ }^{-2}\right]=0 \cdot 037$, and $\left[\mathrm{S}_{5}{ }^{-2}\right]=$ $0 \cdot 330$. These values yield a $\bar{y}$ of $3 \cdot 26$, which is much too large. By introducing $\mathrm{S}_{6}{ }^{-2}$ this discrepancy can be removed.

(c) Saturated in $\mathrm{H}_{2} \mathrm{~S}$ assuming the presence of $\mathrm{HS}_{x}{ }^{-1}$. It follows from Eqn. (17) that if hydropolysulfides are present at $\mathrm{pH} 7.65$ the amounts of hydrosulfide, tetrasulfide, and pentasulfide must be less than computed. The ratios of these last three ions, however, are not changed. An extreme case exists if the only anion in the solution is $\mathrm{HS}_{2}{ }^{-1}$. In this case the $\bar{y}$ would be $2 \cdot 0$; it follows that addition of $\mathrm{HS}_{2}{ }^{-1}$ to any polysulfide solution tends to bring the $\bar{y}$ to $2 \cdot 0$. Thus the assumption that $\mathrm{HS}_{2}{ }^{-1}$ is present would decrease the $\bar{y}$ of $3 \cdot 26$, calculated above, but would not bring it to 1.29 as required by the experimental observations. If the $\bar{y}$ as calculated, assuming the absence of hydropolysulfides, were between $1 \cdot 29$ and $2 \cdot 00$, the inclusion of any hydropolysulfide in the computations would worsen the agreement between experiment and hypothesis. Evidently the introduction of hydropolysulfides into the present discussion will not remove the discrepancies observed.

Final approximation of standard potentials and $\Delta F^{\circ}$ 's of $S_{4}{ }^{-2}, S_{5}{ }^{-2}$, and $S_{6}{ }^{-2}$

The only explanation that the present writer found to be satisfactory was to assume the presence of $\mathrm{S}_{6}{ }^{-2}$. By estimating $E_{5}{ }^{\circ}$ and $E_{4}{ }^{\circ}$ from the data, except for that at $\bar{y}=4.9$ and then estimating the amount of $\mathrm{S}_{6}{ }^{-2}$ needed to bring $\bar{y}$ up to 4.9 at saturation in $\mathrm{S}$ (no $\mathrm{H}_{2} \mathrm{~S}$ added) a preliminary estimate of $E_{6}{ }^{\circ}$ was obtained. By using this estimate for calculations at $\mathrm{pH} 7.65$ (saturated in $\mathrm{S}$ and $\mathrm{H}_{2} \mathrm{~S}$ ) corrections could be estimated, and the corrected values used for the case where no $\mathrm{H}_{2} \mathrm{~S}$ was added. By recycling in this manner estimates were finally obtained which were consistent with all the experimental data. These estimates are as follows:

$$
\begin{array}{ll}
E_{4}{ }^{\circ}=-0.502 ; & 4 \mathrm{~S}^{-2}=\mathrm{S}_{4}{ }^{-2}+6 e^{-1} \\
E_{5}{ }^{\circ}=-0.494 ; & 5 \mathrm{~S}^{-2}=\mathrm{S}_{5}{ }^{-2}+8 e^{-1} \\
E_{6}{ }^{\circ}=-0.486 ; & 6 \mathrm{~S}^{-2}=\mathrm{S}_{6}{ }^{-2}+10 e^{-1}
\end{array}
$$

Estimates of $\Delta F^{\circ}$ for $S_{2}^{-2}$ and $S_{3}^{-2}$.

By assuming an upper limit of about $0.001 \mathrm{M}$ for the concentrations of disulfide and trisulfide ions their free energies of formation can be estimated. The concentrations of $\mathrm{S}_{2}{ }^{-2}$ and $\mathrm{S}_{3}{ }^{-2}$ cannot be higher without controverting earlier assumptions, and may be far less. These and other data are compiled in Table 5. In Fig. 10 the free energies are plotted against the number of $\mathrm{S}$ atoms/ion.

\section{Calculations of distribution of polysulfide ions}

Having derived values of the free energies of all ions present in these solutions, it is now possible to calculate the distribution of species throughout the $\mathrm{pH}$ range 
investigated entirely from theoretical considerations. Since $\mathrm{S}_{2}{ }^{-2}$ and $\mathrm{S}_{3}{ }^{-2}$ are very small in amount, they may be omitted from the equations without serious error. It was possible to get agreement with the experimental data at $\mathrm{pH} 7.65$ without introducing any hydropolysulfides, and consequently these are also presumed to be

Table 5

\begin{tabular}{|c|c|c|c|c|}
\hline ion & $\Delta H^{\mathrm{r}}$ & $E_{z}^{\circ} ;$ reaction & $E^{\circ}$; reaction & $\begin{array}{c}\Delta F^{\circ} \text { from } \\
\text { MaronNy } \\
(1959 \mathrm{~b})\end{array}$ \\
\hline$s^{-2}$ & $21 \cdot 42$ & - & $-0.46444 ; S^{-2}=S+2 e^{-1}$ & $21 \cdot 958$ \\
\hline $\mathrm{S}_{2}^{-2}$ & $22 \cdot 7 \pm 3 \cdot 0$ & $-0.436 ; \quad 2 S^{-3}=S_{2}^{-2}+2 e^{-1}$ & $-0.492 ; \quad \mathrm{S}_{2}-2=2 \mathrm{~S}+2 e^{-1}$ & $19 \cdot 749$ \\
\hline $\mathbf{S}_{3}^{2}-2$ & $21 \cdot 0 \pm 3.0$ & $-0.469 ; \quad 3 \mathrm{~S}^{-2}=\mathrm{S}_{3}^{2}+4 e^{-1}$ & $-0 \cdot 455 ; \quad \mathrm{s}_{3}-2=3 \mathrm{~s}+2 e^{-1}$ & $17 \cdot 968$ \\
\hline$S_{4}^{-2}$ & $16 \cdot 29 \pm 0.10$ & $-0.501_{5} ; 4 S^{-2}=S_{4}-2+6 e^{-1}$ & $-0.353 ; \quad S_{4}^{-2}=4 S+2 e^{-1}$ & $16 \cdot 615$ \\
\hline $\mathrm{S}_{5}-2$ & $15.97 \pm 0.10$ & $-0 \cdot 494_{0} ; 5 \mathrm{~S}^{-2}=\mathrm{S}_{5}^{-2}+8 e^{-1}$ & $-0.346 ; \quad S_{5}-2=5 \mathrm{~S}+2 e^{-1}$ & $15 \cdot 689$ \\
\hline $\mathbf{s}_{8}^{-2}$ & $16 \cdot 36 \pm 0.10$ & $-0.486_{4} ; 6 S^{-2}=S_{8}^{-2}+10 e^{-1}$ & $-0.355 ; \quad \mathrm{S}_{8}^{-2}=6 \mathrm{~S}+2 e^{-1}$ & $(>17.0 ?)^{*}$ \\
\hline
\end{tabular}

* If less than $17 \cdot 0$ appreciable anounts would be present at saturation in $\mathbf{s}$.

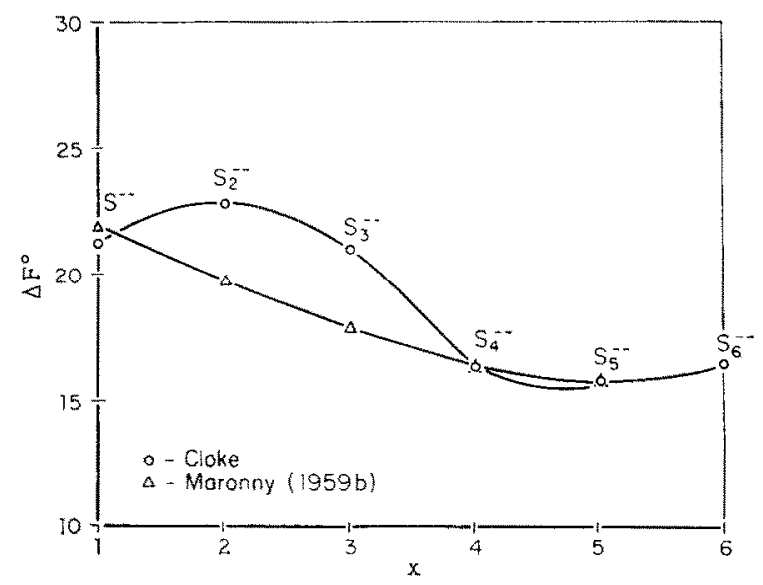

Fig. 10. Plat of Gibbs froe energy of formation of sulfide and polysulfide ions vs. no. of $\mathrm{S}$ atoms in ion.

negligible. From the free energies the following equilibrium constants were evaluated:

$$
\begin{aligned}
\left(\mathrm{H}^{+1}\right)\left(\mathrm{HS}^{-1}\right) /\left(\mathrm{H}_{2} \mathrm{~S}\right) & =K_{1}=10^{-6 \cdot 99}, \\
\left(\mathrm{H}^{+1}\right)\left(\mathrm{S}^{-2}\right) /\left(\mathrm{HS}^{-1}\right) / & =K_{2}=10^{-13 \cdot 50}, \\
\left(\mathrm{H}^{+1}\right)\left(\mathrm{OH}^{-1}\right) & =K_{W}=10^{-14 \cdot 00}, \\
\left(\mathrm{~S}_{5}^{-2}\right)^{3}\left(\mathrm{~S}^{-2}\right) /\left(\mathrm{S}_{4}^{-2}\right)^{4} & =K_{5}^{\prime}=10^{-3.23} \\
\left(\mathrm{~S}_{6}^{-2}\right)^{4}\left(\mathrm{~S}^{-2}\right) /\left(\mathrm{S}_{5}^{-2}\right)^{5} & =K_{6}^{\prime}=10^{-5 \cdot 33}
\end{aligned}
$$

In addition there are within the experimental error the two relations:

$$
\left[\mathrm{Na}^{+1}\right]=\left[\mathrm{OH}^{-1}\right]+\left[\mathrm{HS}^{-1}\right]+2\left[\mathrm{~S}^{-2}\right]+2\left[\mathrm{~S}_{4}^{-2}\right]+2\left[\mathrm{~S}_{5}^{-2}\right]+2\left[\mathrm{~S}_{6}^{-2}\right]
$$

and $\bar{y}=\left\{\left[\mathrm{HS}^{-1}\right]+\left[\mathrm{S}^{-2}\right]+4\left[\mathrm{~S}_{4}^{-2}\right]+5\left[\mathrm{~S}_{5}^{-2}\right]+6\left[\mathrm{~S}_{8}^{-2}\right]\right\} /$

$$
\left\{\left[\mathrm{HS}^{-1}\right]+\left[\mathrm{S}^{-2}\right]+\left[\mathrm{S}_{4}^{-2}\right]+\left[\mathrm{S}_{5}^{-2}\right]+\left[\mathrm{S}_{8}^{-2}\right]\right\}
$$


This amounts to 7 eqns. in 10 unknowns since the activity coefficients are known. An additional eqn. is readily obtained by specifying the concentration, i.e. the molarity of sodium ion. The choice of the two remaining eqns. depends on the circumstances.

Calculation of the hydrolysis curve was made by writing

$$
\left[\mathrm{OH}^{-1}\right]=\left[\mathrm{HS}^{-1}\right],
$$

and either assigning a definite value to $\bar{y}$ or specifying that the solution is saturated in $\mathrm{S}$. In the latter case the reaction $\mathrm{S}_{4}{ }^{-2}+\mathrm{S}=\mathrm{S}_{5}{ }^{-2}$ and the corresponding eqn.,

$$
\left(\mathrm{S}_{5}{ }^{-2}\right) /\left(\mathrm{S}_{4}{ }^{-2}\right)=K_{5}{ }^{\prime \prime}=1 \cdot 74,
$$

are both valid. The constant for the reaction $\mathrm{S}_{5}{ }^{-2}+\mathrm{S}=\mathrm{S}_{6}{ }^{-2}$ can be obtained from equations (21), (22), (26).

Along the $\mathrm{S}$ saturation curve use was made of Eqn. (26) and the $\mathrm{pH}$ specified. At the acid end of this curve the pressure of $\mathrm{H}_{2} \mathrm{~S}$ was specified instead of $\mathrm{pH}$. For

\begin{tabular}{|c|c|c|c|c|c|c|c|c|c|c|c|c|c|c|c|}
\hline $\bar{y}$ & {$\left[\mathrm{~S}_{6}{ }^{-2}\right]$} & {$\left[S_{5}-2\right]$} & {$\left[\mathrm{S}_{4}^{-2}\right]$} & {$\left[\mathrm{S}^{-2}\right]$} & {$\left[\mathrm{HS}^{-1}\right]$} & {$\left[\mathrm{H}_{2} \mathrm{~S}\right]$} & $\mathrm{pS}_{6}$ & $\mathrm{pS}_{5}$ & $\mathrm{pS}_{4}$ & $\mathrm{pS}$ & pHS & $\mathrm{pH}_{2} \mathrm{~s}$ & $\mathrm{pH}$ & {$\left[\mathrm{Na}^{+1}\right]$} & Eh \\
\hline \multicolumn{16}{|c|}{ Hydrolysis Curve, $\left[\mathrm{OH}^{-1}\right]=\left[\mathrm{HS}^{-1}\right]$} \\
\hline 4.9 & 0.10 & 0.234 & 0.158 & - & 0.002 & - & $1 \cdot 34$ & 1.06 & $1 \cdot 30$ & $5 \cdot 25$ & $2 \cdot 88$ & 7.01 & $11 \cdot 12$ & $1 \cdot 0$ & -0.308 \\
\hline $4 \cdot 5$ & 0.044 & $0 \cdot 189$ & 0.258 & 0.001 & 0.008 & 一 & $1 \cdot 73$ & $1 \cdot 15$ & 1.09 & $4 \cdot 13$ & $2 \cdot 32$ & $7 \cdot 01$ & $11 \cdot 69$ & $1 \cdot 0$ & -0.350 \\
\hline $4 \cdot 0$ & 0.010 & $0 \cdot 104$ & 0.343 & 0.010 & 0.034 & - & $2 \cdot 38$ & 1.41 & 0.96 & $2 \cdot 84$ & $1 \cdot 67$ & 7.01 & $12 \cdot 33$ & $1 \cdot 0$ & -0.400 \\
\hline $3 \cdot 0$ & 0.002 & 0.038 & 0.279 & 0.081 & 0.099 & - & $3 \cdot 15$ & $1 \cdot 84$ & 1.05 & 1.91 & $1 \cdot 20$ & $7 \cdot 01$ & 12.80 & 1.0 & -0.437 \\
\hline $2 \cdot 0$ & & .013 & $0 \cdot 148$ & 0.191 & $0 \cdot 149$ & - & $3 \cdot 85$ & $2 \cdot 32$ & $1 \cdot 32$ & $1 \cdot 54$ & $1 \cdot 02$ & $7 \cdot 01$ & $12 \cdot 98$ & $1 \cdot 0$ & -0.454 \\
\hline
\end{tabular}

Table 6

\begin{tabular}{|c|c|c|c|c|c|c|c|c|c|c|c|c|c|c|c|}
\hline $4 \cdot 5$ & 0.102 & 0.221 & 0.149 & - & 0.055 & - & $1 \cdot 37$ & 1.08 & $1 \cdot 32$ & $5 \cdot 27$ & $1 \cdot 46$ & $4 \cdot 16$ & $9 \cdot 69$ & $1 \cdot 0$ & -0.308 \\
\hline $4 \cdot 0$ & 0.093 & $0 \cdot 205$ & 0.137 & - & $0 \cdot 130$ & - & $1 \cdot 40$ & $1 \cdot 12$ & $1 \cdot 36$ & $5 \cdot 31$ & $1 \cdot 08$ & $3 \cdot 36$ & $9 \cdot 27$ & $1 \cdot 0$ & -0.306 \\
\hline $3 \cdot 0$ & 0.074 & 0.159 & 0.107 & $\longrightarrow$ & $0 \cdot 320$ & 0.002 & 1.51 & 1.22 & 1.46 & $5 \cdot 41$ & $0 \cdot 69$ & $2 \cdot 48$ & 8.78 & $1 \cdot 0$ & -0.303 \\
\hline $2 \cdot 0$ & 0.044 & 0.095 & 0.064 & 一 & 0.594 & 0.011 & 1.73 & $1 \cdot 44$ & 1.68 & $5 \cdot 63$ & 0.42 & $1 \cdot 72$ & $8 \cdot 29$ & 1.0 & -0.297 \\
\hline $1 \cdot 3$ & 0.016 & 0.036 & 0.024 & 一 & 0.849 & 0.056 & $2 \cdot 15$ & 1.87 & $2 \cdot 11$ & $6 \cdot 06$ & 0.26 & 1.00 & 7.72 & 1.0 & -0.284 \\
\hline
\end{tabular}

S saturation curve

\begin{tabular}{|c|c|c|c|c|c|c|c|c|c|c|c|c|c|c|c|}
\hline $\begin{array}{l}4 \cdot 5 \\
4 \cdot 5\end{array}$ & $\begin{array}{l}0.057 \\
0.088\end{array}$ & $\begin{array}{l}0 \cdot 204 \\
0 \cdot 219\end{array}$ & $\begin{array}{l}0 \cdot 229 \\
0 \cdot 170\end{array}$ & - & $\begin{array}{l}0.018 \\
0.046\end{array}$ & - & $\begin{array}{l}1.62 \\
1.43\end{array}$ & $\begin{array}{l}1 \cdot 12 \\
1 \cdot 09\end{array}$ & $\begin{array}{l}1 \cdot 14 \\
1 \cdot 27\end{array}$ & $\begin{array}{l}4 \cdot 42 \\
5 \cdot 03\end{array}$ & $\begin{array}{l}1.92 \\
1.53\end{array}$ & $\begin{array}{l}5 \cdot 93 \\
4 \cdot 54\end{array}$ & $\begin{array}{l}11 \cdot 00 \\
10 \cdot 00\end{array}$ & $\begin{array}{l}1 \cdot 0 \\
1 \cdot 0\end{array}$ & $\begin{array}{l}-0.339 \\
-0.316\end{array}$ \\
\hline \multicolumn{16}{|c|}{$\bar{y}=4.0$ curve } \\
\hline $4 \cdot 0$ & 92 & 160 & $0 \cdot 272$ & 0.001 & $0 \cdot 0$ & - & 1.91 & $1 \cdot 22$ & $1 \cdot 06$ & $3 \cdot 81$ & $1 \cdot 31$ & $5 \cdot 32$ & 11 & $1 \cdot 0$ & -0 \\
\hline $4 \cdot 0$ & 0.062 & $0 \cdot 195$ & $0 \cdot 191$ & 一 & $0 \cdot 106$ & - & 1.58 & $1 \cdot 14$ & $1 \cdot 21$ & $4 \cdot 67$ & $1 \cdot 17$ & $4 \cdot 18$ & $10 \cdot 00$ & $1 \cdot 0$ & -0.330 \\
\hline
\end{tabular}

$\bar{y}=4 \cdot 5$ curve

\begin{tabular}{|c|c|c|c|c|c|c|c|c|c|c|c|c|c|c|c|}
\hline $3 \cdot 0$ & 0.004 & 0.063 & $0-302$ & 0.026 & 0.195 & - & $2 \cdot 76$ & $1 \cdot 62$ & $1 \cdot 01$ & $2 \cdot 40$ & 0.90 & $5 \cdot 91$ & $12 \cdot 00$ & 1.0 & -0.417 \\
\hline $3 \cdot 0$ & 0.012 & $0 \cdot 102$ & $0 \cdot 259$ & 0.003 & 0.247 & 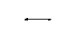 & $2 \cdot 28$ & $1 \cdot 42$ & 1.08 & $3 \cdot 30$ & 0.80 & $4 \cdot 81$ & $11 \cdot 00$ & 1.0 & -0.383 \\
\hline $3 \cdot 0$ & 0.032 & $0 \cdot 139$ & 0.188 & 一 & $0 \cdot 282$ & - & 1.87 & $1 \cdot 28$ & $1 \cdot 22$ & $4 \cdot 25$ & 0.75 & $3 \cdot 76$ & $10 \cdot 00$ & $1 \cdot 0$ & -0.347 \\
\hline $3 \cdot 0$ & 0.050 & $0 \cdot 154$ & $0 \cdot 145$ & - & $0 \cdot 302$ & . & $1 \cdot 67$ & $1 \cdot 24$ & $1 \cdot 33$ & $4 \cdot 82$ & 0.72 & $3 \cdot 13$ & $9 \cdot 40$ & $1 \cdot 0$ & -0.325 \\
\hline \multicolumn{16}{|c|}{$\bar{y}=2 \cdot 0 \operatorname{curv} \theta$} \\
\hline $2 \cdot 0$ & 0 & & & & & 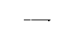 & $3 \cdot 2 y$ & $1 \cdot 1$ & $1 \cdot 20$ & & & & $12 \cdot 00$ & $1 \cdot 0$ & \\
\hline $2 \cdot 0$ & 0.004 & 0.050 & 0.180 & $0 \cdot 007$ & 0 . & $\ldots$ & $2 \cdot 74$ & 1.7 & $1 \cdot 23$ & 2 & 0. & $4 \cdot 49$ & $11 \cdot 00$ & $1 \cdot 0$ & 97 \\
\hline $2 \cdot 0$ & 0.012 & 0.074 & 0.140 & 一 & 0.545 & - & $2 \cdot 28$ & 1.55 & $1 \cdot 34$ & 3.96 & 0.46 & $3 \cdot 47$ & $10 \cdot 00$ & $1 \cdot 0$ & -0.359 \\
\hline $2 \cdot 0$ & 0.028 & 0.094 & 0.094 & - & 0.572 & 0.002 & 1.92 & $1 \cdot 45$ & $1 \cdot 52$ & 4.94 & 0.44 & $2 \cdot 45$ & $9 \cdot 00$ & 1.0 & -0.322 \\
\hline
\end{tabular}

$\bar{y}=3 \cdot 0$ curve 
solutions saturated in $\mathrm{H}_{2} \mathrm{~S}$ but unsaturated in $\mathrm{S}$ the pressure of $\mathrm{H}_{2} \mathrm{~S}$ and the $\bar{y}$ were assigned. For those solutions which do not correspond to any of these situations $\bar{y}$ and $\mathrm{pH}$ were specified. Thus in all cases it is possible to choose 10 eqns. in 10 unknowns. These were solved by the method of successive approximations by substituting into each eqn. in turn and making appropriate adjustments until all 10 were satisfied. The results are compiled in Table 6 for solutions $1 \mathrm{M}$ in sodium ion.

This data can be plotted in various ways. Three of the more interesting methods are shown in Figs. 11, 13, and 14. In Fig. 11 the concentrations of the various ionic

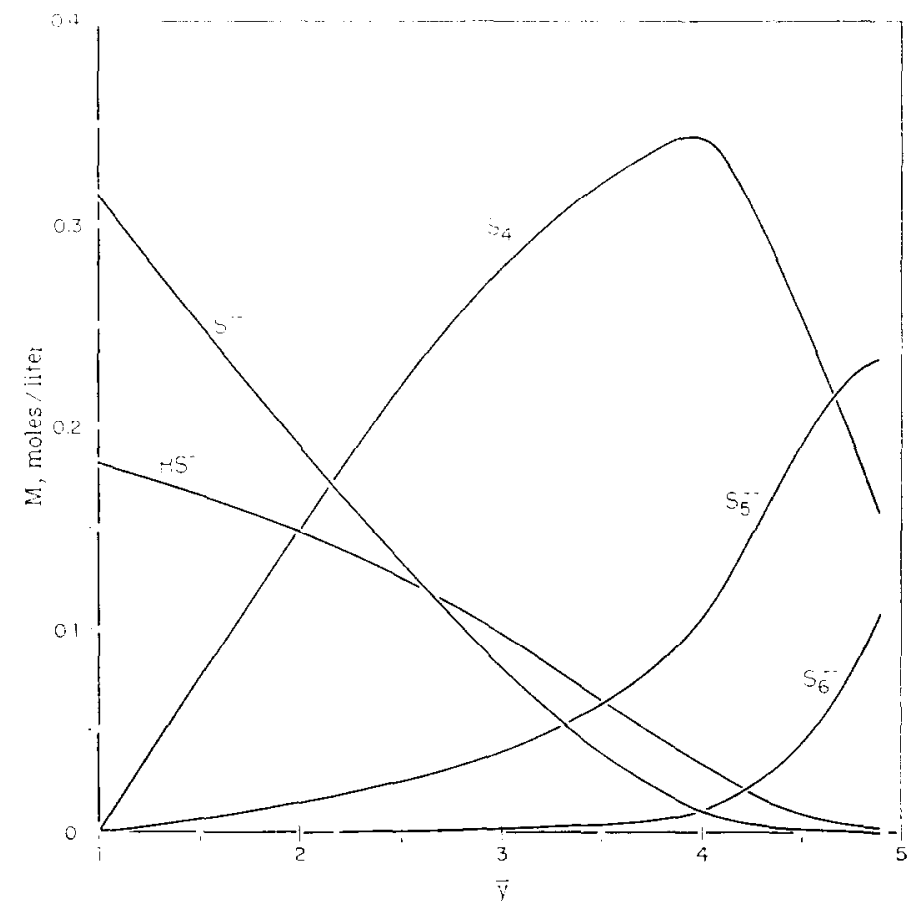

Fig. 11. Distribution of sulfur species on hydrolysis curve of $0.5 \mathrm{M}$ sodium polysulfide solutions.

species are plotted for the hydrolysis of sodium polysulfides as a function of $\bar{y}$. For comparison Fig. 12 shows the distribution as given by MARONNY for a concentration in sodium ion of $0.186 \mathrm{M}$. Although $\mathrm{S}_{2}{ }^{-2}$ and $\mathrm{S}_{3}{ }^{-2}$ are undoubtedly present, the work reported here suggests that they are negligible in amount. The entire difference between Figs. 11 and 12 rests on a difference of only $0.1 \mathrm{pH}$ and a small discrepancy between the observed and calculated (assuming no $\mathrm{S}_{6}{ }^{-2}$ ) maximum $\bar{y}$ values. It seems reasonable that the actual distribution lies somewhere between these two models.

Figure 13 shows the computed equilibrium concentrations of the various sulfide species in polysulfide solutions at $\mathrm{pH} 10$ as a function of $\bar{y}$. The shift in the maximum for $\mathrm{S}_{4}{ }^{-2}$ to $\bar{y}=3.5$ is particularly interesting. At lower $\mathrm{pH}$ values this intermediate maximum disappears entirely and the concentration of $\mathrm{S}_{4}{ }^{-2}$ increases continuously from $\bar{y}=1$ to a maximum where the solution is saturated in $\mathrm{S}$. 
In Fig. 14 the changes in concentrations of $\mathrm{S}$ species are shown at a constant $\bar{y}$ of 4.0 as the $\mathrm{pH}$ changes from that on the $\mathrm{S}$ saturation curve $(\mathrm{pH} 9)$ to that on the hydrolysis curve $(\mathrm{pH} 12 \cdot 33)$.

\section{Discussion}

The present study has led to a new interpretation of the relative amounts of polysulfide ions in sodium polysulfide solutions. In spite of this the measured $\mathrm{pH}$ and Eh values correspond well with those reported previously by MaronnY

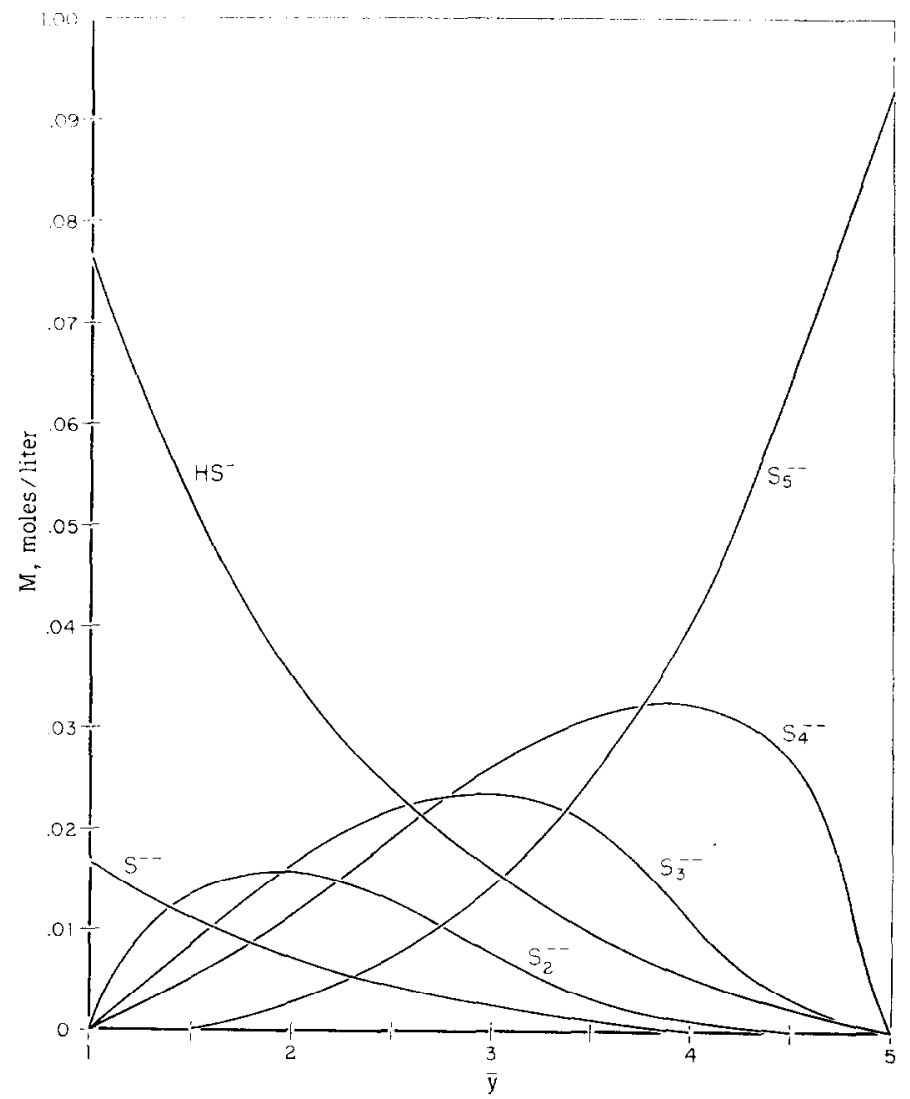

Fig. 12. Distribution of sulfur species on hydrolysis curve of 0.093 M sodium polysulfide solutions after MARONNY (1959b).

(1959a,b) or by Maronny and Valensi (1959), and the free energies of formation of the higher polysulfide ions do not differ greatly from MARONNY's (1959b) values. The difference in interpretation rests on quantities that are difficult to measure so that it seems worthwhile to consider the problem from other points of view.

In this respect it is interesting to consider the work of FEHÉR et al. As mentioned above, when he added sodium polysulfide solutions to concentrated $\mathrm{HCl}$, he did not obtain any $\mathrm{H}_{2} \mathrm{~S}_{2}$ or $\mathrm{H}_{2} \mathrm{~S}_{3}$ as determined by Raman spectra (FEHÉR and BAUDLER, 1949 ) in the resulting oils even though the $\bar{y}$ of the initial polysulfide solution was 


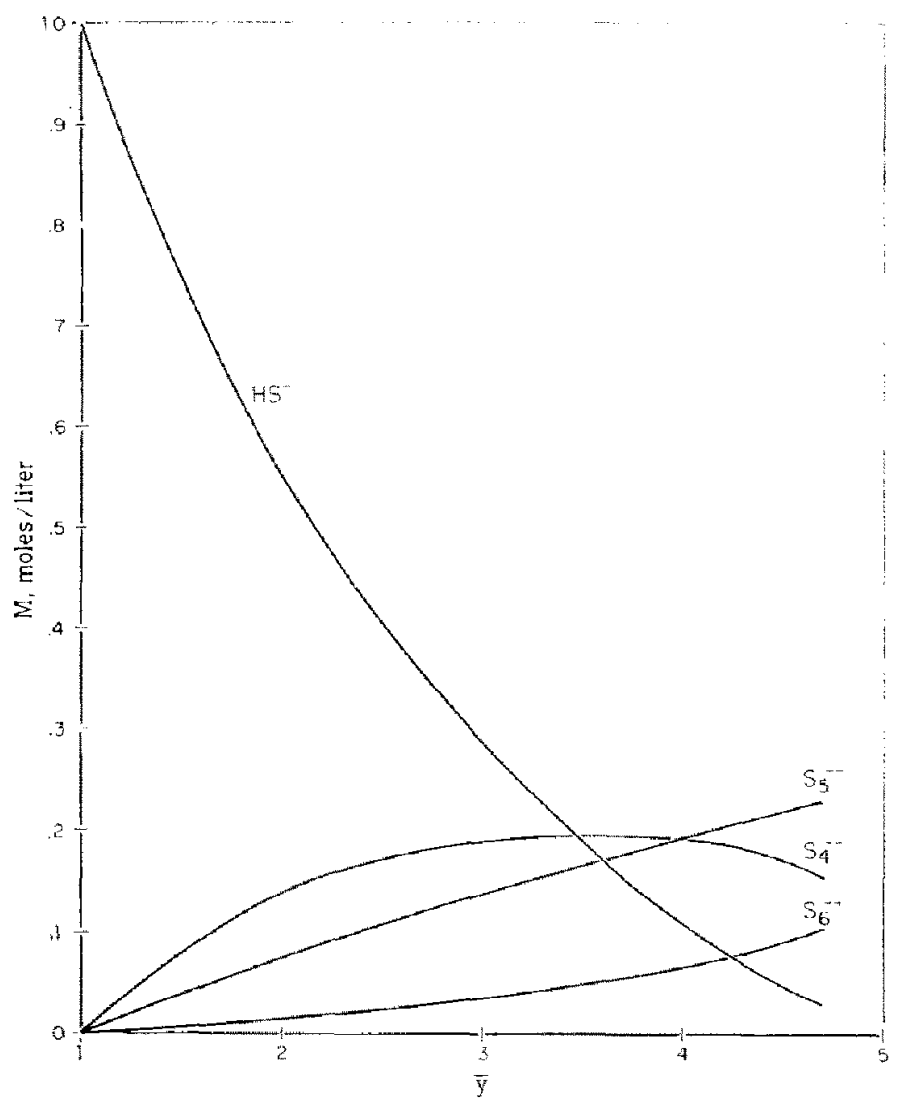

Fig. 13. Distribution of sulfur species at $\mathrm{pH} 10$ in sodium polysulfide solutions $1.0 \mathrm{M}$ in $\mathrm{Na}^{+1}$.

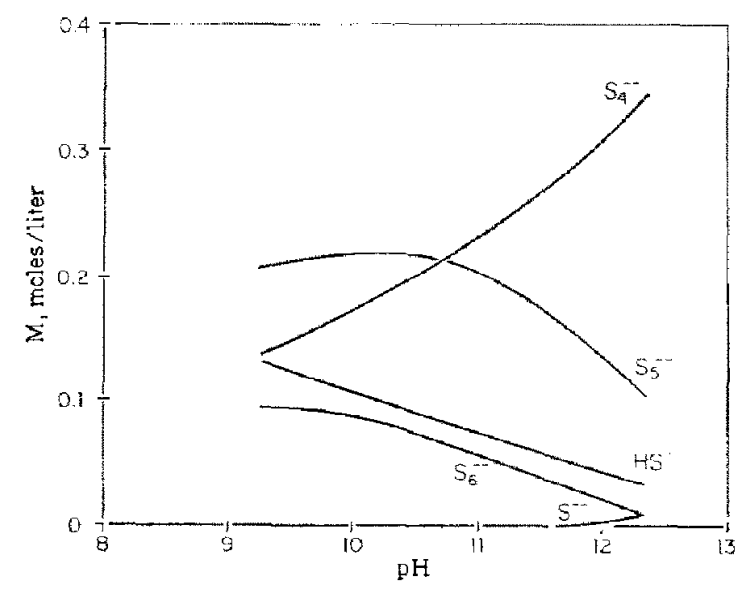

Fig. 14. Distribution of sulfur species for $\ddot{y}=4.0$ as a function of $\mathrm{pH}$ in sodium polysulfide solutions $1.0 \mathrm{M}$ in $\mathrm{Na}^{+1}$. 
low. In terms of the distribution suggested here this is to be expected since there is no appreciable amount of $\mathrm{S}_{2}^{-2}$ or $\mathrm{S}_{3}{ }^{-2}$ ion in the initial solution. In terms of MARoNvy's distribution, however, rather large amounts of both $\mathrm{S}_{2}^{-2}$ and $\mathrm{S}_{3}{ }^{-2}$ must be completely and rapidly converted to $\mathrm{H}_{2} \mathrm{~S}$ and $\mathrm{H}_{2} \mathrm{~S}_{4}$ or $\mathrm{H}_{2} \mathrm{~S}_{5}$. FEHÉR and coworkers (e.g. FEHÉR and BAUDLER, 1947, 1949) on the other hand found this type of splitting reaction to take place slowly. There is no doubt that some splitting does occur, however, as is evident from the fact that some of the persulfide oils have $\bar{y}$ values up to $5 \cdot 5$ or 6 . These relations do lend more support to the present model than to MaRonnY's.

In an attempt to verify the distribution proposed, absorption spectra of polysulfide solutions with $\bar{y}$ 's of 2,3 , and 4 were made. The results were not very satisfactory due to the rapid oxidation to $\mathrm{S}$ at the dilution required to transmit any light at all at the absorption peaks. One broad peak was found at about $310 \mathrm{~m} \mu$ and a second about one half as strong at about $365 \mathrm{~m} \mu$. They were in the same positions for all three solutions. FeHÉr et al. (FeHÉr and Baudler, 1947, 1949; FeHér and Winkmaus, 1956) found the Raman spectra of $\mathrm{H}_{2} \mathrm{~S}_{4}$ and $\mathrm{H}_{2} \mathrm{~S}_{5}$ were very similar to each other, and to higher sulfanes but differed sharply from those of $\mathrm{H}_{2} \mathrm{~S}_{2}$ and $\mathrm{H}_{2} \mathrm{~S}_{3}$. By analogy it might be expected that the absorption peaks of $\mathrm{S}_{4}^{-2}$ and $\mathrm{S}_{5}{ }^{-2}$ are similar to each other but differ from those of $\mathrm{S}_{2}{ }^{-2}$ and $\mathrm{S}_{3}{ }^{-2}$. Since no shifts were found in the peaks, the absorption data lend a little support to the proposed distribution.

FEн ÉR and his co-workers have also concluded that the polysulfides are chain structures. Moreover, as seems very reasonable the properties of the hydrogen polysulfides (or sulfanes) are smooth, approximately linear functions of the chain length or become more and more alike as the length increases. A reasonable extrapolation of MARonnY's (1959b) free energy data can be made in keeping with this principle by referring to Fig. 10. The estimate thus obtained for the free energy of formation of hexasulfide ion is about $15.4 \mathrm{kcal} / \mathrm{mole}$. This value, however, implies that $\mathrm{S}_{6}{ }^{-2}$ is present in solutions saturated in sulfur to an even greater extent than in the distribution proposed here.

The author feels that the available evidence favors the distribution and free energy values proposed here more strongly than the corresponding ones of MARONNY. Perhaps a study using Raman spectra, or an investigation of maximum $\bar{y}$ values in dioxane-water solutions would help to clarify the problem.

\section{SUMmary}

Calculations based on potential measurements with glass, platinum, and silversilver sulfide electrodes have led to a different interpretation of the distribution of polysulfide ions in aqueous solution than that proposed previously. This leads to values of the free energy of formation differing from those of MARONnY by $180 \mathrm{cal}$ for $\mathrm{S}_{5}{ }^{-2}$ to 3000 cal for $\mathrm{S}_{3}{ }^{-2}$. The changes in distribution even though very marked are based on small differences in $\mathrm{pH}$ or in the maximum $\bar{y}$. Analogies to the work with hydrogen polysulfides favor the free energy values proposed here.

Acknowledgements - The work has been performed while the author held a post-doctoral research fellowship sponsored by the Committee on Experimental Geology and Geophysics, Harvard University. I wish to express my appreciation for their support and especially for the continued interest of Professor Robert M. Garkels of Harvard University. In addition I wish to thank 
Professor Garrels and Professor Edgar F. Westrum, Jr. of The University of Michigan for reading and commenting on the manuscript and MARGARET E. CUTHBERT for checking the calculations for arithmetic errors.

\section{References}

Arntson R. H., Dickson F. W. and Tunell G. (1958) Saturation Curves of Orthorhombic Sulfur in the System S-Na $\mathrm{S}_{2}-\mathrm{H}_{2} \mathrm{O}$ at $25^{\circ}$ and $50^{\circ} \mathrm{C}$. Science 128, 716-718.

Arntson R. H., Dickson F. W. and Tunell G. (1960) Systems $\mathrm{S}-\mathrm{Na}_{2} \mathrm{O}-\mathrm{H}_{2} \mathrm{O}$ and $\mathrm{S}-\mathrm{H}_{2} \mathrm{O}$ : Application to the Mode of Origin of Natural Alkaline Polysulfide and Thiosulfate Solutions. Amer. J. Sci. 258, 574-582.

Barnes H. L. (1958) Ore Solutions. Carnegie Inst. Wash. Yearb. 57, 234-240.

Barton P. B. Jr. (1957) Some limitations on the possible composition of the ore-forming fluid. Econ. Geol. 52, 333-353.

ELLIS A. J. and Golding R. M. (1959) Spectrophotometric determination of the acid dissociation constants of hydrogen sulfide. J. Chem. Soc. 127-130.

Fetŕr F. and Baudler M. (1947) Beiträge zur Chemie des Schwefels, III Mitteilung, Präparative Darstellung und Eigenschaften des Wasserstofftrisulfids, Z. anorg. Chem. 254, 251-254.

Fehér F. and Baudler M. (1949) Beiträge zur Chemie des Schwefels, VIII, Über das Wasserstoffpentasulfid $\mathrm{H}_{2} \mathrm{~S}_{5}$ und das Wasserstoffhexasulfid $\mathrm{H}_{2} \mathrm{~S}_{6}$. Z. anorg. Chem. 258, 132-149.

Fenér F. and Berthold H. J. (1953a) Beiträge zur Chemie des Schwefels, XIII, Die titrimetrische Bestimmung reiner Alkalipolysulfide, Z. anal. Chem. 138, 245-249.

Fenér F. and Berthold H. J. (1953b) Beiträge zur Chemie des Schwefels, XIV, Über das System Natrium-Schwefel, Z. anorg. Chem. 273, 144-160.

Fenér F. and Berthold H. J. (1953c) Beiträge zur Chemie des Schwefels XV, Über das System Kalium-Schwefel, Z. anorg. Chem. 274, 223-233.

Fenér F. and Berthold H. J. (1954) Beiträge zur Chemie des Schwefels, XX, Die Raumehemie des Sulfide von Natrium und Kalium, $Z$. anorg. Chem. 275, 241-248.

Ferér F. and Laue W. (1956) Beiträge zur Chemie des Schwefels, XXX, Über die Darstellung von Rohsulfanen, $Z$. anorg. Chem. 288, 103-112.

Fenér F., Laute W. and Winkmaus G. (1956) Beiträge zur Chemie des Schwefels, XXX, Über die Darstellung der Sulfane $\mathrm{H}_{2} \mathrm{~S}_{2}, \mathrm{H}_{2} \mathrm{~S}_{3}, \mathrm{H}_{2} \mathrm{~S}_{4}$, und $\mathrm{H}_{2} \mathrm{~S}_{5}$. Z. anorg. Chem. 288, 113-122.

Femér F., Laue W. and Winkhaus G. (1957) Beiträge zur Chemie des Schwefels, XXXIV, Molvolumina und Molrefraktionen der Sulfane und ihre Abhängigkeit von der Kettenlänge. $Z$. anorg. Chem. 290, 52-57.

Fehér F. and Naused K. (1956) Beiträge zur Chemie des Schwefels, XXVI, Über die Systeme Rubidium-Schwefel und Caesium-Schwefel. Z. anorg. Chem. 283, 79-87.

FenÉr F. and Wrnkraus G. (1956) Beiträge zur Chemie des Schwefels, XXXI, U̇ber die Darstellung der Sulfane $\mathrm{H}_{2} \mathrm{~S}_{5}, \mathrm{H}_{2} \mathrm{~S}_{6}, \mathrm{H}_{2} \mathrm{~S}_{7}$ und $\mathrm{H}_{2} \mathrm{~S}_{8}$. Z. anorg. Chem. 288, 123-130.

Garrels R. M, and NagSER C. R. (1958) Equilibrium distribution of dissolved sulphur species in water at $25^{\circ} \mathrm{C}$ and 1 atm total pressure. Geochim. et Cosmochim. Acta 15, 113-130.

Grmbletr F. G. R. and Monk C. B. (1954) E.M.F. studies of electrolytic dissociation, Part 7, Some alkali and alkaline earth metal hydroxides in water. Trans. Faraday Soc. 50, 965-972.

Goates J. R., Cole A. G., Gray E. L. and Faux N. D. (1951) Thermodynamic Properties of Silver Sulfide, $J$. Amer. chem. Soc. 73, 707-708.

ILARNed II. S. and OWen B. B. (1958) The Physical Chemistry of Electrolytic Solutions, 3rd ed., Reinhold, New York.

Kielland J. (1937) Individual Activity Coefficients of Ions in Aqueous Solutions, $J$. Amer. chem. Soc. 59, 1675-1678.

Knox J. (1908) A study of the sulphur anion and of complex sulphur anions, Trans. Faraday Soc. 4, $29-50$.

Konopik N. and LebERL O. (1949) Die zweite Dissoziationskonstante von Schwefelwasserstoff, Mh. Chem. 80, 781-787.

Kubli H. (1946) Die Dissoziation von Schwefelwasserstoff, Helv. chim. acta 29, 1962-1973.

Kury .J. W., Zielen A. J. and Latimer W. M. (1953) Heats of Formation and Entropies of HS ${ }^{-}$ and $s^{--}$. Potential of Sulfide-Sulfur Couple, J. electrochem. Soc. 100, 468-470. 
Küster F. W. and Heberlein F. (1905) Beiträge zur Kenntnis der Polysulfide I, Z. anorg. Chem. 43, 53-84.

LATIMER W. M. (1952) The Oxidation States of the Elements and their Potentials in Aqueous Solutions. 2nd ed., Prentice-Hall, New York.

Mac InNes. D. A. (1939) The Principles of Electrochemistry, Reinhold, New York, 140.

MARONNY G. (1959a) Constantes de dissociation del'hydrogène sulfuré, Electrochim. Acta 1, 58-69.

MaronNy G. (1959b) Fonctions thermodynamiques standards des ions sulfurés et polysulfurés en solution aqueuse, $J$. Chim. phys. 56, 140-151, 202-221.

Maronny G. and Valensi G. (1955) The standard electrode potential of the Pt- $\mathrm{S} / \mathrm{S}_{5}{ }^{2-}$ electrode. Proc., Sixth Meeting, Int. Comm. Electrochem. Thermodynam. and Kinet. (CITCE), Butterworths Scientific Publ., London, 180-189.

Maronny G. and Vatensi G. (1956) Recherches calorimétriques sur la chaleur de formation du pentasulfure de sodium en solution aqueuse. Bull. Soc. chim. Fr. 23, 752.

Maronny G. and VALENSI G. (1957) Calorimetric determination of thermodynamical functions of the $\mathrm{S}_{5}{ }^{2-}$ ion, Proc., Seventh Meeting, Int. Comm. Electrochem. Thermodynam. and Kin. (CITCE), Butterworths Scientific Publ., London, 266-274.

Maronny G. and Valensi G. (1958) Détermination de la tension standard du couple $\mathrm{S}_{5}{ }^{2-} / \mathrm{s}_{4}{ }^{2-}$, Proc., Eighth Meeting, Int. Comm. Electrochem. Thermodynam. and Kinet. (CITCE), Butterworths Scientific Publ., London, 204-217.

Maronny G. and Valensi G. (1959) Fonctions thermodynamiques standard des ions mono et polysulfurés en solution aqueuse, Proc., Ninth Meeting, Int. Comm. Electrochem. Thermodynam. and Kinet. (CITCE), Butterworths Scientific Publ., London, 155-165.

Natarajax R. (1958) Personal Communication. Eh-pII diagram for $\mathrm{Cu}-\mathrm{Fe}-\mathrm{S}-\mathrm{II}_{2} \mathrm{O}$ system.

NodDack $W$. and Wrabetz $K$. (1955) Über das elektrochimische Verhalten einiger Schwermetallsulfide. Z. Electrochem. 59, 96-102.

Peschanski D. and Valensi G. (1949) Contribution a l'électrochimie des solution aqueuses de polysulfures, $J$. Chim. phys. 46, 602-619.

Robinson R. A. and Stokes R. H. (1949) The role of hydration in the Debye-Hückel theory. Ann. N.Y. Acad. Sci. 51, 593-604.

Sato M. (1959) The Oxidation of Sulfide Ore Bodies with Special Reference to Self-Potentials. ('Thesis, Univ. of Minn.) Univ. Microfilm Service, Ann Arbor, Michigan.

Valensi G. (1951) Contribution au diagramme potentiel pH du Soufre, Proc., Second Meeting, Int. Comm. Electrochem. Thermodynam. and Kinet. (CITCE), Libreria Editrice Politecnica Cesare Tamburini, Milan, 51-68.

Zobell C. E. (1946) Studies on redox potential of marine sediments, Amer. Ass. petrol. Geol. Bull. 30, 495. 